\title{
Separation of Fischer-Tropsch Wax from Catalyst by Supercritical Extraction
}

\begin{tabular}{l|l|ll} 
Report Type: & FINAL & Reporting Period Start Date: 09/01/1994 End Date: 12/31/1998
\end{tabular} Principal Author(s): Patrick C. Joyce and Mark C. Thies

Clemson University

Submitting

Organization(s)

Name \& Address
Department of Chemical Engineering

123 Earle Hall

Clemson, SC 29634-0909

\section{North Carolina State University}

Department of Chemical Engineering

Diane Sherrard, Joan Biales, Peter Kilpatrick

and George Roberts

(2)

Raleigh, NC 27695-7905 


\section{Disclaimer}

This report was prepared as an account of work sponsored by an agency of the United States Government. Neither the United States Government nor any agency thereof, nor any of their employees, makes any warranty, express or implied, or assumes any legal liability or responsibility for the accuracy, completeness, or usefulness of any information, apparatus, product, or process disclosed, or represents that its use would not infringe privately owned rights. Reference herein to any specific commercial product, process, or service by trade name, trademark, manufacturer, or otherwise does not necessarily constitute or imply its endorsement, recommendation, or favoring by the United States Government or any agency thereof. The views and opinions of authors expressed herein do not necessarily state or reflect those of the United States Government or any agency thereof. 


\section{Executive Summary}

The objective of this research project was to evaluate the potential of supercritical fluid (SCF) extraction for the recovery and fractionation of the wax product from the slurry bubble column (SBC) reactor of the Fischer-Tropsch (F-T) process. The wax, comprised mostly of branched and linear alkanes with a broad molecular weight distribution up to $\mathrm{C}_{100}$, is to be extracted with a hydrocarbon solvent that has a critical temperature near the operating temperature of the SBC reactor, i.e., 200-300 ${ }^{\circ} \mathrm{C}$.

Aspen Plus ${ }^{\mathrm{TM}}$ was used to perform process simulation studies on the proposed extraction process, with Redlich-Kwong-Soave (RKS) being used for the thermodynamic property model. Because of the lack of experimental data available for solvent-long alkane systems, all binary interaction parameters (i.e., $k_{i j}$ 's) had to be set to 0.00 . Both high and low solvent-to-wax ratios were investigated. Results indicate that for the solvents hexane and heptane, our proposed process can be operated at conditions such that two key concerns are satisfied: One, operating temperatures can be kept low enough such that no catalyst deactivation occurs, and two, no buildup of high molecular weight waxes occurs in the reactor.

Although these simulation results were encouraging, they are only useful in a qualitative sense because of the lack of experimental data on which the phase equilibrium calculations were based. Thus, another objective of this research project was to both measure and model phase equilibrium data for systems relevant to the SCF extraction process--model F-T waxes with supercritical solvents. To this end, vapor and liquid equilibrium compositions were measured for binary mixtures of hexane with hexadecane, 1-hexadecene, 1-hexadecanol, tetracosane $\left(n-\mathrm{C}_{24} \mathrm{H}_{50}\right)$, hexatriacontane $\left(n-\mathrm{C}_{36} \mathrm{H}_{74}\right)$, and squalane (a branched $\mathrm{C}_{30} \mathrm{H}_{62}$ alkane) at temperatures from 200 to $350{ }^{\circ} \mathrm{C}$ and at pressures up to the mixture critical point for a given temperature. For all the systems examined, Type I phase behavior (i.e., vapor-liquid equilibria with no liquid-liquid immiscibilities) was observed. As the binary system asymmetry increased, vapor-phase solubilities decreased and the size of the two-phase region increased. Comparison of results for the three waxes containing a $\mathrm{C}_{16}$ "backbone" indicate that the effect of the hydroxyl group on solubilities and phase behavior is still significant for waxes that are 16 carbons long; the effect of the double bond, however, has already become negligible. Thus, any 
thermodynamic model developed for our extraction process can safely neglect alkenes present in the F-T wax.

Modeling the experimental data focused primarily on two equations of state: Peng-Robinson (P-R) and SAFT. Peng-Robinson was found to accurately represent the phase behavior of the $\mathrm{C}_{16}$ "backbone" waxes. Unfortunately, results for systems containing $\mathrm{C}_{24}$ and larger waxes indicate that cubic equations cannot be used to even correlate these systems, and thus by extension, systems containing any real F-T waxes (which contain more than $50 \% \mathrm{C}_{36}+$ waxes). To improve $\mathrm{P}-\mathrm{R}$, the three pure component parameters $a_{c}, b$, and $\kappa$ were fit to pure component vapor pressures and liquid densities (instead of being determined from critical properties). This led to a substantial improvement in the ability of P-R to correlate data for systems containing long-chain alkanes. Unfortunately, relatively large $k_{i j}$ 's were still required to fit the data. Our results suggest it may be possible to estimate the interaction parameters, but more data on other solvent + model wax systems is required to confirm this hypothesis.

A modern equation of state based on statistical mechanics and molecular simulation, SAFT, was found to adequately correlate liquid-phase compositions for the alkane systems examined. Furthermore, a small, nearly constant $k_{i j}$ of $0.02-0.03$ was found to give the best fit to all the systems examined at all temperatures, making the equation truly predictive for bubble-point compositions. Unfortunately, SAFT consistently underpredicts the wax solubilitities in the vapor phase and overpredicts the pressure of the mixture critical points. No straightforward modifications of SAFT, such as were applied to P-R, can be applied to improve its correlative ability.

In summary, we have made comprehensive VLE measurements for short alkane + long alkane systems over a wide range of pressures and temperatures, dramatically increasing the amount of high-quality data available for these simple, yet highly relevant systems. In addition, our work has demonstrated that, surprisingly, no current thermodynamic model can adequately predict VLE behavior for these systems. Thus, process simulations (such as those for our proposed SCF extraction process) that incorporate these systems can currently only give results that are qualitative at best. Although significant progress has been made in the past decade, more experimental and theoretical work remain to be done before the phase equilibria of asymmetric alkane mixtures can be predicted with confidence. 


\section{Technical Objectives}

The objective of this research project is to evaluate the potential of supercritical fluid (SCF) extraction for the recovery and fractionation of the wax product from the slurry bubble column (SBC) reactor of the Fischer-Tropsch (F-T) process. The wax, comprised mostly of branched and linear alkanes with a broad molecular weight distribution up to $\mathrm{C}_{100}$, will be extracted with a hydrocarbon solvent that has a critical temperature near the operating temperature of the $\mathrm{SBC}$ reactor, i.e., $200-300{ }^{\circ} \mathrm{C}$. Initial work is being performed using $n$-hexane as the solvent.

Previous researchers have shown that the supercritical solvent is able to dissolve the F-T wax at conditions that do not entrain the solid catalyst. However, this in itself does not ensure that the process would be commercially viable. For example, the extraction must be controlled so as not to favor the accumulation of high molecular weight wax compounds, and the accompanying wax gelation that would occur in the reactor. Another concern is the lack of phase equilibrium data available in the literature for F-T wax/solvent mixtures. Such data are needed as input into process simulation packages if we are to have any confidence in the simulation of a SCF extraction process.

Therefore, three major tasks were undertaken to assist in the evaluation of our proposed SCF extraction process. Task 1: Equilibrium solubility measurements for model F-T wax components in supercritical fluids at conditions representative of those in a SBC reactor. Task 2: Thermodynamic modeling of the measured VLE data for extending our results to real wax systems. Task 3: Process design studies of our proposed process. Additional details of the task structure are given below.

Task 1: Equilibrium Solubility Measurements

a. apparatus modification and construction.

b. experimental measurements of selected model systems.

c. design and construction of new apparatus for measuring VLE of $\mathrm{C}_{36}+$ alkanes with hexane.

Task 2: Thermodynamic Modeling

a. modeling VLE data using cubic equations of state.

b. examination of theoretically based models, including the SAFT equation.

Task 3: Process Design Studies

a. process configuration studies using the ASPEN PLUS simulation package. 


\section{Detailed Description of Technical Progress}

\section{Task 1a. Apparatus Modification and Construction}

A continuous-flow apparatus was used to measure vapor-liquid equilibrium for the systems of interest. A flow apparatus was chosen for this work (1) to allow us to more accurately measure the low concentrations of model wax in the vapor phase at the lower temperatures and (2) to minimize residence times at the higher temperatures and thus reduce the extent to which wax degradation would occur.

Description of Apparatus and Experimental Procedure. A simplified schematic of the flow apparatus is depicted in Figure 1. Unless otherwise noted, all tubing was 1.59 $\mathrm{mm}$ o.d. with an i.d. of $0.76 \mathrm{~mm}$. For an experimental run, the model wax and n-hexane were pumped at a combined volumetric flow rate between 150 and $250 \mathrm{~mL} / \mathrm{hr}$. The two components are preheated within the isothermal nitrogen bath in separate lines. The $\mathrm{n}$ hexane is preheated in an 8-m length of tubing and the model wax in a shorter section that is only $1 \mathrm{~m}$ long to minimize degradation at high temperatures. The two components are then combined in an impingement mixing tee. In order to promote further mixing, the model wax + hexane mixture subsequently flows through two lengths of $1.5-\mathrm{m}$ tubing separated by a $1.75 \mathrm{~mm}$ i.d. x $3-\mathrm{m}$ section. The combined streams then enter the view cell.

For samples that are solids at room temperature (i.e., 1-hexadecanol, tetracosane, hexatriacontane), modifications to the apparatus and sample collection technique were required to prevent solids precipitation. The model wax feed reservoir, feed lines, and the reciprocating pump head are heated with electrical heating tape (Glas-Col, Cat. No. DET025) and maintained at $75-100{ }^{\circ} \mathrm{C}$. This heating tape is also used to maintain the temperature of the sampling lines exiting the bath at about $75{ }^{\circ} \mathrm{C}$. The last $5 \mathrm{~cm}$ of sampling line is not wrapped with tape so that the line can be inserted into the sealed sample collection vial. To prevent this portion of the line from plugging due to solidification, the last $8 \mathrm{~cm}$ of each sampling line is made of copper, which remains hot by conduction. Because the sample lines are heated, better sealing and colder collection vials are required to prevent hexane losses. An improved seal is obtained by first threading the copper sample lines and screwing on tapped vial caps; the caps are then permanently sealed to the sample line with epoxy. Colder collection temperatures $\left(\sim-10{ }^{\circ} \mathrm{C}\right)$ are 
obtained by cooling the sample vials in a mixture of ice and salt.

The two phases separate within the cell, and are then drawn off from sample ports located at the top and bottom of the view cell. Lines run from the sample ports out of the oven and connect to micrometering valves (Autoclave Engineers, Model 60VRMM). The top-phase micrometering valve is used to control the pressure, while the bottom-phase micrometering valve is used to control the liquid level within the view cell.

The view cell was designed and constructed at Clemson to operate at temperatures up to $673 \mathrm{~K}$ and pressures up to 350 bar. A 12-ml cell volume was used to decrease the model wax residence time in the oven and also to minimize the quantity of material needed for an experimental measurement. The cell windows are made of high-temperature aluminosilicate glass (Hoya Optics) and are sealed with graphite gaskets (Grafoil, UCAR). Both the mixing section and the view cell are located inside a nitrogen bath.

Safety issues. Several safety features are incorporated into the bath design: (1) A polycarbonate shield is mounted over the viewing window. In addition, the view cell is viewed indirectly with a mirror. (2) A high-temperature shut-off independent of the normal temperature control scheme is used. (3) When running the apparatus, the bath is continuously purged with nitrogen. The oxygen concentration inside the bath is regularly monitored by GC and is maintained below 2 mol \% oxygen (well below the lower explosion limit).

Temperature and Pressure Measurement Scheme. The temperatures of the feed to the cell and of the top and bottom phases were measured with three Type $\mathrm{K}$ differential thermocouples referenced to an aluminum block located in the bath. The temperature of the block itself was measured with a secondary-standard PRT (Burns Engineering). A full description of the temperature measurement and calibration scheme, which is capable of measuring temperatures to an accuracy of $\pm 0.1 \mathrm{~K}$, is given elsewhere (Stevenson, 1994). Some variation of the temperature in the view cell and of the feed is characteristic of a flow apparatus. Based on the accuracy of the temperature measurements and accounting for the variations during an experimental run, the temperatures reported in this work are accurate to better than $\pm 0.3 \mathrm{~K}$. The system pressure was measured using a Bourdon tube gauge (Heise, Model CM, 0-1000 psig). The pressure gauge was calibrated against a Budenburg dead weight gauge (Model $380 \mathrm{H}$ ) to an accuracy of $0.04 \%$ of the indicated pressure. For a majority of samples, the cell pressure was controlled to within \pm 0.14 bar, 
resulting in an experimental uncertainty in the pressure measurements of \pm 0.17 bar.

To verify the accuracy of the temperature and pressure measurements, the pure component vapor pressure of hexane was measured at two temperatures. The experiments were performed as follows. First, the system was held at a constant temperature. Hexane was then pumped into the system using an Isco pump. The pressure was slowly increased until liquid appeared at the feed port. This was the measured vapor pressure. Also, the cell would be filled with liquid at a pressure above the vapor pressure of hexane. The pressure would slowly be decreased until bubbles appeared in the feed. Using both methods, the pressure agreed within \pm 0.1 bar. As can be seen in Table 1 , the measured properties are in good agreement with the values found in the literature.

Table 1. Comparison of experimental and literature values for vapor pressures of hexane.

\begin{tabular}{ccc}
\hline Temperature $(\mathrm{K})$ & Measured $\mathrm{P}^{\text {sat }}($ bar $)$ & Literature $\mathrm{P}^{\text {sat }}($ bar $)$ \\
\hline 471.3 & 17.61 & 17.52 \\
481.8 & 20.71 & 20.67 \\
\hline
\end{tabular}

As a further check on accuracy, the critical point of hexane was measured. Initially, the constant-temperature bath was held $0.5 \mathrm{~K}$ below the critical point of hexane. Hexane was then pumped into the system and the pressure was increased until the vapor pressure of hexane was reached. Then, the temperature was slowly increased and again the pressure would be increased up to the vapor pressure. The experiment was repeated until the critical temperature of hexane was reached. As the pressure was increased at the critical temperature, critical opalescense was observed. The temperature and pressure were measured when critical opalescence occurred. Table 2 shows the experimental and literature values for the critical temperature and pressure of hexane. As can be seen, the two are in good agreement. 
Table 2. Comparison of experimental and literature values for the critical point of hexane.

\begin{tabular}{cccc}
\hline $\mathrm{T}_{\mathrm{c}}{ }^{\text {exp }}(\mathrm{K})$ & $\mathrm{P}_{\mathrm{c}}{ }^{\text {exp }}(\mathrm{bar})$ & $\mathrm{T}_{\mathrm{c}}^{\text {lit }}(\mathrm{K})$ & $\mathrm{P}_{\mathrm{c}}^{\text {lit }}(\mathrm{bar})$ \\
\hline 507.5 & 30.38 & 507.6 & 30.25 \\
\hline
\end{tabular}

Verification of Equilibrium Conditions in the View Cell. To verify that measured vapor and liquid compositions were indeed at equilibrium, samples were collected at different flow rates for several of the measured binary systems. If any nonequilibrium conditions (such as entrainment of the liquid phase) existed in the apparatus, varying the flow rates would alter the measured phase compositions. As can be seen by the examples given in Tables 3 and 4, no variation within the experimental accuracy of the data was ever observed. Therefore, it is concluded that equilibrium conditions were present for all binary systems that were measured.

Table 3. Measured equilibrium compositions and nominal flow rates for the hexane +1 hexadecanol system at $472.1 \mathrm{~K}$ and 11.36 bar.

\begin{tabular}{ccc}
\hline & \multicolumn{2}{c}{ mole fraction 1-hexadecanol } \\
total flow rate $(\mathrm{mL} / \mathrm{h})$ & liquid & vapor \\
\hline 100 & 0.324 & 0.00257 \\
200 & 0.328 & 0.00254 \\
300 & 0.328 & 0.00262
\end{tabular}

Table 4. Measured equilibrium compositions and nominal flow rates for the hexane + squalane system at $576.4 \mathrm{~K}$ and 34.82 bar.

\begin{tabular}{ccc}
\hline & \multicolumn{2}{c}{ mole fraction squalane } \\
total flow rate $(\mathrm{mL} / \mathrm{h})$ & liquid & vapor \\
\hline 100 & 0.243 & 0.0101 \\
200 & 0.244 & 0.0100 \\
300 & 0.242 & 0.0101
\end{tabular}

Measurement of Mixture Critical Points. Mixture critical pressures were obtained by the observation of critical opalescence within the equilibrium cell. To obtain critical point compositions, critical opalescence phenomena were maintained in the view cell while samples were collected as previously described. We have found that the flow apparatus can be used to measure both mixture critical pressures and critical point compositions to an accuracy comparable to our measurements for conventional vapor and liquid compositions. Results are believed to be reliable because (1) the intense reddish color 
associated with opalescence is observed only over a narrow pressure range not exceeding \pm 0.10 bar, and (2) changes in the overall system composition of less than $\pm 2 \%$ in the minor component cause the complete disappearance and reappearance of critical opalescence in the view cell.

Task 1b. Experimental Measurements for Model Wax Compounds in Supercritical Hexane Measured compositions and corresponding pressures for binary mixtures of hexane with hexadecane, 1-hexadecene, 1-hexadecanol, tetracosane $\left(n-\mathrm{C}_{24} \mathrm{H}_{50}\right)$, hexatriacontane $\left(n-\mathrm{C}_{36} \mathrm{H}_{74}\right.$ ), and squalane (a branched $\mathrm{C}_{30} \mathrm{H}_{62}$ ) at temperatures from 472 to $623.0 \mathrm{~K}$ are given in Tables 5-10 and are depicted in pressure-composition diagrams in Figures 2-7. These results have also been reported in the open literature (Joyce and Thies, 1997, 1998; Joyce et al., 1998, 1999a, 1999b). Considering all sources of error, the reported liquid and vapor compositions are accurate to better than \pm 3 and $\pm 4 \%$ deviation in the minor component, respectively. Measured mixture critical compositions are accurate to $\pm 4 \%$ deviation in the minor component. Information unique to a particular binary system is given below.

Hexane + 1-Hexadecene. 1-hexadecene was found to oligomerize at the elevated temperatures of the experiments. The average percent oligomerization (by mass) in the liquid phase for each isotherm was found to be $1.0 \%, 1.3 \%$, and $2.1 \%$ at $472.1,524.7$, and $572.5 \mathrm{~K}$, respectively. Oligomers are estimated to range in size from dimers to pentamers. No oligomers were detected in the vapor phase. Thus, we believe that the impact of oligomerization on phase equilibrium was small, and within the experimental uncertainties in composition. The reported liquid-phase 1-hexadecene compositions were calculated by assuming that the oligomers were 1-hexadecene.

In order to examine the effect of the double bond on phase behavior, results for hexane +1 -hexadecene are compared to the hexane + hexadecane binary. As seen by comparing Tables 5 and 6, 1-hexadecene solubilities in the vapor phase at $472 \mathrm{~K}$ are consistently higher (by about 7-10\%) than those for hexadecane, but for the two highertemperature isotherms essentially no differences are observed. This trend is consistent with the vapor pressure differences between the two $\mathrm{C}_{16}$ compounds: at $472 \mathrm{~K}$, the vapor pressure for 1 -hexadecene is $7 \%$ higher than for hexadecane, and at the two higher 
temperatures the difference is significantly less. For the liquid-phase compositions, little difference was observed between the two systems, with most points agreeing to within a deviation of $3 \%$.

Hexane + 1-Hexadecanol. By comparing results for hexadecane to 1hexadecanol, a direct comparison of the effect of the added hydroxyl group on the system phase behavior can be made (see Tables 5 and 7). The data indicate that even with an alkane as long as hexadecane, the impact on the phase behavior of adding an $\mathrm{OH}$ group is still significant. For example, hexadecanol has about one-third the solubility of hexadecane in the vapor phase at $472 \mathrm{~K}$ and about one-half the solubility at $572 \mathrm{~K}$. In summary, then, results for the two substituted $\mathrm{C}_{16}$ systems indicate that the effect of the hydroxyl group is significant for F-T waxes that are 16 carbons long, while the effect of the double bond is negligible.

Table 5. Vapor-liquid equilibrium properties for the hexane + hexadecane system.

\begin{tabular}{|c|c|c|c|c|c|}
\hline \multirow[b]{2}{*}{ press., bar } & \multicolumn{2}{|c|}{ mole fraction hexadecane } & \multirow[b]{2}{*}{ press., bar } & \multicolumn{2}{|c|}{ mole fraction hexadecane } \\
\hline & liquid & vapor & & liquid & vapor \\
\hline & $\mathrm{T}=472.3 \mathrm{~K}$ & & & $\mathrm{~T}=572.5 \mathrm{~K}$ & \\
\hline 6.18 & 0.548 & 0.0142 & 7.91 & 0.804 & 0.193 \\
\hline 7.91 & 0.462 & 0.0107 & 14.80 & 0.629 & 0.117 \\
\hline 9.63 & 0.363 & 0.00818 & 21.70 & 0.486 & 0.0887 \\
\hline 11.36 & 0.277 & 0.00621 & 25.14 & 0.419 & 0.0828 \\
\hline 13.08 & 0.195 & 0.00462 & 28.59 & 0.356 & 0.0801 \\
\hline 14.80 & 0.123 & 0.00299 & 32.04 & 0.296 & 0.0804 \\
\hline 16.53 & 0.0543 & 0.00145 & 35.49 & 0.240 & 0.0848 \\
\hline 17.35 & 0.0230 & 0.000605 & 38.93 & 0.170 & 0.107 \\
\hline & & & $39.45^{\mathrm{a}}$ & 0.137 & 0.137 \\
\hline & $\mathrm{T}=524.4 \mathrm{~K}$ & & & $\mathrm{~T}=623.0 \mathrm{~K}$ & \\
\hline 7.91 & 0.676 & 0.0628 & 11.36 & 0.818 & 0.364 \\
\hline 11.36 & 0.564 & 0.0463 & 16.53 & 0.719 & 0.274 \\
\hline 14.80 & 0.450 & 0.0360 & 21.70 & 0.628 & 0.233 \\
\hline 18.25 & 0.362 & 0.0304 & 25.14 & 0.566 & 0.210 \\
\hline 21.70 & 0.276 & 0.0266 & 28.59 & 0.505 & 0.206 \\
\hline 25.14 & 0.195 & 0.0234 & 32.04 & 0.443 & 0.201 \\
\hline 28.59 & 0.132 & 0.0218 & 35.49 & 0.383 & 0.213 \\
\hline 32.04 & 0.0717 & 0.0212 & 37.21 & 0.349 & 0.228 \\
\hline $33.76^{\mathrm{a}}$ & 0.0306 & 0.0306 & $38.24^{\mathrm{a}}$ & 0.279 & 0.279 \\
\hline
\end{tabular}


Table 6. Vapor-liquid equilibrium properties for the hexane +1 -hexadecene system.

\begin{tabular}{|c|c|c|c|c|c|}
\hline \multirow[b]{2}{*}{ press., bar } & \multicolumn{2}{|c|}{ mole fraction 1-hexadecene } & \multirow[b]{2}{*}{ press., bar } & \multicolumn{2}{|c|}{ mole fraction 1-hexadecene } \\
\hline & liquid & vapor & & liquid & vapor \\
\hline & $\mathrm{T}=472.1 \mathrm{~K}$ & & & $=572.5$ & \\
\hline 7.91 & 0.457 & 0.0115 & 7.84 & 0.784 & 0.200 \\
\hline 9.63 & 0.364 & 0.00890 & 13.08 & 0.656 & 0.129 \\
\hline 11.36 & 0.275 & 0.00683 & 18.25 & 0.546 & 0.101 \\
\hline 13.08 & 0.195 & 0.00512 & 23.42 & 0.446 & 0.0869 \\
\hline 14.80 & 0.119 & 0.00340 & 28.59 & 0.350 & 0.0809 \\
\hline 16.53 & 0.0500 & 0.00160 & 33.76 & 0.267 & 0.0820 \\
\hline 17.42 & 0.0213 & 0.000518 & 38.93 & 0.185 & 0.0992 \\
\hline & & & $40.07^{\mathrm{a}}$ & 0.137 & 0.137 \\
\hline & $\mathrm{T}=524.7 \mathrm{~K}$ & & & & \\
\hline 7.91 & 0.667 & 0.0647 & \multicolumn{3}{|c|}{ a Vapor-liquid critical point } \\
\hline 13.60 & 0.503 & 0.0410 & & & \\
\hline 18.25 & 0.363 & 0.0308 & & & \\
\hline 21.70 & 0.277 & 0.0272 & & & \\
\hline 25.14 & 0.199 & 0.0241 & & & \\
\hline 28.59 & 0.129 & 0.0219 & & & \\
\hline 32.04 & 0.0679 & 0.0210 & & & \\
\hline $33.76^{\mathrm{a}}$ & 0.0326 & 0.0326 & & & \\
\hline
\end{tabular}

Table 7. Vapor-liquid equilibrium properties for the hexane +1 -hexadecanol system.

\begin{tabular}{|c|c|c|c|c|c|}
\hline \multirow[b]{2}{*}{ press., bar } & \multicolumn{2}{|c|}{ mole fraction 1-hexadecanol } & \multirow[b]{2}{*}{ press., bar } & \multicolumn{2}{|c|}{ mole fraction 1-hexadecanol } \\
\hline & liquid & vapor & & liquid & vapor \\
\hline & $\mathrm{T}=472.1 \mathrm{~K}$ & & & $\mathrm{~T}=572.4 \mathrm{~K}$ & \\
\hline 6.18 & 0.628 & 0.00452 & 7.91 & 0.826 & 0.0865 \\
\hline 7.91 & 0.526 & 0.00373 & 11.36 & 0.756 & 0.0663 \\
\hline 9.63 & 0.428 & 0.00310 & 14.80 & 0.678 & 0.0551 \\
\hline 11.36 & 0.327 & 0.00258 & 18.25 & 0.598 & 0.0492 \\
\hline 13.08 & 0.226 & 0.00207 & 23.15 & 0.504 & 0.0445 \\
\hline 14.80 & 0.134 & 0.00155 & 28.59 & 0.393 & 0.0432 \\
\hline 16.53 & 0.0589 & 0.000788 & 35.49 & 0.288 & 0.0470 \\
\hline 17.35 & 0.0231 & 0.000279 & 38.93 & 0.215 & 0.0558 \\
\hline & & & 42.38 & 0.144 & 0.0749 \\
\hline & & & $43.21^{\mathrm{a}}$ & 0.109 & 0.109 \\
\hline & $\mathrm{T}=524.4 \mathrm{~K}$ & & & $\mathrm{~T}=623.0 \mathrm{~K}$ & \\
\hline 7.91 & 0.666 & 0.0250 & 11.36 & 0.835 & 0.184 \\
\hline 11.36 & 0.588 & 0.0188 & 18.25 & 0.713 & 0.134 \\
\hline 14.80 & 0.481 & 0.0160 & 21.70 & 0.659 & 0.127 \\
\hline 18.25 & 0.393 & 0.0139 & 28.59 & 0.541 & 0.114 \\
\hline 21.70 & 0.308 & 0.0129 & 32.04 & 0.491 & 0.113 \\
\hline 25.14 & 0.220 & 0.0128 & 35.49 & 0.442 & 0.114 \\
\hline 28.59 & 0.140 & 0.0123 & 38.93 & 0.374 & 0.116 \\
\hline 32.04 & 0.0688 & 0.0134 & 42.38 & 0.325 & 0.126 \\
\hline $34.35^{\mathrm{a}}$ & 0.0302 & 0.0302 & $46.41^{\mathrm{a}}$ & 0.199 & 0.199 \\
\hline
\end{tabular}


Table 8. Vapor-liquid equilibrium properties for the hexane + tetracosane system.

\begin{tabular}{|c|c|c|c|c|c|}
\hline \multirow[b]{2}{*}{ press., bar } & \multicolumn{2}{|c|}{ mole fraction tetracosane } & \multirow[b]{2}{*}{ press., bar } & \multicolumn{2}{|c|}{ mole fraction tetracosane } \\
\hline & liquid & vapor & & liquid & vapor \\
\hline & $\mathrm{T}=473.0 \mathrm{~K}$ & & & $\mathrm{~T}=573.4 \mathrm{~K}$ & \\
\hline 6.18 & 0.532 & 0.000460 & 7.91 & 0.6914 & 0.0185 \\
\hline 7.91 & 0.450 & 0.000406 & 14.80 & 0.5486 & 0.0127 \\
\hline 9.63 & 0.359 & 0.000348 & 18.25 & 0.4750 & 0.0119 \\
\hline 11.35 & 0.276 & 0.000301 & 21.70 & 0.4130 & 0.0116 \\
\hline 13.08 & 0.204 & 0.000257 & 25.14 & 0.3649 & 0.0118 \\
\hline 14.80 & 0.128 & 0.000201 & 32.11 & 0.2672 & 0.0134 \\
\hline 16.53 & 0.0606 & 0.000142 & 38.93 & 0.1856 & 0.0177 \\
\hline 17.42 & 0.0325 & 0.000094 & 44.10 & 0.1224 & 0.0274 \\
\hline & & & $46.72^{\mathrm{a}}$ & 0.0591 & 0.0591 \\
\hline & $\mathrm{T}=524.3 \mathrm{~K}$ & & & $\mathrm{~T}=622.9 \mathrm{~K}$ & \\
\hline 7.91 & 0.629 & 0.00389 & 7.91 & 0.7676 & 0.0652 \\
\hline 11.35 & 0.501 & 0.00319 & 14.80 & 0.6380 & 0.0430 \\
\hline 14.80 & 0.408 & 0.00287 & 21.70 & 0.5160 & 0.0367 \\
\hline 18.25 & 0.328 & 0.00270 & 28.59 & 0.4286 & 0.0359 \\
\hline 21.70 & 0.254 & 0.00272 & 35.49 & 0.3499 & 0.0386 \\
\hline 25.14 & 0.182 & 0.00298 & 42.38 & 0.2721 & 0.0457 \\
\hline 28.59 & 0.124 & 0.00352 & 45.83 & 0.2334 & 0.0530 \\
\hline 32.04 & 0.066 & 0.00446 & 48.59 & 0.2007 & 0.0630 \\
\hline $35.28^{\mathrm{a}}$ & 0.015 & 0.015 & $51.83^{\mathrm{a}}$ & 0.1109 & 0.1109 \\
\hline
\end{tabular}

${ }^{\text {a }}$ Vapor-liquid critical point

Table 9. Vapor-liquid equilibrium properties for the hexane + hexatriacontane system.

\begin{tabular}{|c|c|c|c|c|c|}
\hline \multirow[b]{2}{*}{ press., bar } & \multicolumn{2}{|c|}{ mole fraction hexatriacontane } & \multirow[b]{2}{*}{ press., bar } & \multicolumn{2}{|c|}{ mole fraction hexatriacontane } \\
\hline & liquid & vapor & & liquid & vapor \\
\hline & $\mathrm{T}=521.7 \mathrm{~K}$ & & & $\mathrm{~T}=621.8 \mathrm{~K}$ & \\
\hline 7.91 & 0.591 & 0.0000795 & 7.91 & 0.765 & 0.00466 \\
\hline 13.08 & 0.411 & 0.0000777 & 14.80 & 0.626 & 0.00347 \\
\hline 18.25 & 0.292 & 0.0000883 & 25.14 & 0.449 & 0.00364 \\
\hline 23.42 & 0.199 & 0.000146 & 35.49 & 0.330 & 0.00493 \\
\hline 28.59 & 0.117 & 0.000310 & 45.83 & 0.240 & 0.00812 \\
\hline 33.76 & 0.0376 & 0.00115 & 56.17 & 0.160 & 0.0157 \\
\hline 35.14 & 0.0191 & 0.00231 & 62.38 & 0.116 & 0.0306 \\
\hline $35.42^{\mathrm{a}}$ & $--{ }^{b}$ & $--{ }^{b}$ & $64.51^{\mathrm{a}}$ & 0.0702 & 0.0702 \\
\hline & $\mathrm{T}=573.1 \mathrm{~K}$ & & & & \\
\hline 7.84 & 0.711 & 0.000773 & & & \\
\hline 14.80 & 0.535 & 0.000619 & & & \\
\hline 21.70 & 0.412 & 0.000745 & & & \\
\hline 28.59 & 0.301 & 0.00103 & & & \\
\hline 35.49 & 0.221 & 0.00179 & & & \\
\hline 42.38 & 0.165 & 0.00331 & & & \\
\hline 49.28 & 0.102 & 0.00841 & & & \\
\hline $53.48^{\mathrm{a}}$ & 0.0358 & 0.0358 & & & \\
\hline
\end{tabular}


Table 10. Vapor-liquid equilibrium properties for the hexane + squalane system.

\begin{tabular}{|c|c|c|c|c|c|}
\hline \multirow[b]{2}{*}{ press., bar } & \multicolumn{2}{|c|}{ mole fraction squalane } & \multirow[b]{2}{*}{ press., bar } & \multicolumn{2}{|c|}{ mole fraction squalane } \\
\hline & liquid & vapor & & liquid & vapor \\
\hline & $\mathrm{T}=469.8 \mathrm{~K}$ & & & $\mathrm{~T}=574.6 \mathrm{~K}$ & \\
\hline 5.52 & 0.564 & 0.000173 & 10.00 & 0.677 & 0.00915 \\
\hline 6.89 & 0.474 & 0.000152 & 15.10 & 0.534 & 0.00779 \\
\hline 8.27 & 0.392 & 0.000131 & 19.99 & 0.450 & 0.00727 \\
\hline 9.45 & 0.321 & 0.000121 & 25.17 & 0.387 & 0.00746 \\
\hline 10.34 & 0.287 & 0.000113 & 30.34 & 0.300 & 0.00864 \\
\hline 10.69 & 0.271 & 0.000111 & 34.82 & 0.243 & 0.0101 \\
\hline 12.07 & 0.213 & 0.0000975 & 38.95 & 0.198 & 0.0130 \\
\hline 13.24 & 0.159 & 0.0000960 & 42.40 & 0.155 & 0.0162 \\
\hline 13.44 & 0.150 & 0.0000939 & 46.26 & 0.110 & 0.0262 \\
\hline 15.38 & 0.0781 & 0.0000620 & 46.95 & 0.0986 & 0.0303 \\
\hline 16.55 & 0.0437 & 0.0000397 & $48.23^{\mathrm{a}}$ & 0.0543 & 0.0543 \\
\hline 17.31 & 0.0219 & 0.0000065 & & & \\
\hline & $\mathrm{T}=524.3 \mathrm{~K}$ & & 8.27 & $\begin{array}{c}\mathrm{T}=623.3 \mathrm{~K} \\
0.761\end{array}$ & 0.0362 \\
\hline 8.62 & 0.572 & 0.00189 & 15.17 & 0.643 & 0.0256 \\
\hline 11.38 & 0.486 & 0.00161 & 21.72 & 0.527 & 0.0238 \\
\hline 16.13 & 0.369 & 0.00155 & 28.61 & 0.429 & 0.0242 \\
\hline 21.03 & 0.266 & 0.00169 & 35.51 & 0.340 & 0.0260 \\
\hline 25.17 & 0.187 & 0.00186 & 42.40 & 0.272 & 0.0319 \\
\hline 28.89 & 0.122 & 0.00232 & 49.30 & 0.199 & 0.0455 \\
\hline 34.13 & 0.0457 & 0.00461 & 51.37 & 0.174 & 0.0547 \\
\hline 35.16 & 0.0294 & 0.00627 & 53.43 & 0.144 & 0.0733 \\
\hline $35.65^{\mathrm{a}}$ & 0.0147 & 0.0147 & $54.81^{\mathrm{a}}$ & 0.104 & 0.104 \\
\hline
\end{tabular}

The results for all of our binary system measurements can be succinctly summarized in the form of a pressure vs. temperature projection, see Figure 8. For comparison, the excellent early work of Pak and Kay (1972) is also given. Critical curves for each binary are shown; the curves are simply smoothed fits to the measured mixture critical points. Using the classification system of van Konynenburg and Scott (1980), we see that all systems exhibit Type I phase behavior (i.e., continuous critical curves with no liquid-liquid immiscibility) with the critical curve running through a maximum in pressure. As expected, as the asymmetry of the binary increased, the maximum pressure of the critical curve also increased. However, no liquid-liquid immiscibility was ever observed. Peters and co-workers (1989) have examined the onset of LLE caused by system asymmetry in mixtures containing light alkanes (methane, ethane, and propane) and longchain alkanes. By extrapolation, they estimate that to observe LLE with hexane, the longchain alkane would need to be larger than $n-\mathrm{C}_{60}$. Figure 8 also illustrates how the critical curves for hexane + tetracosane and hexane + squalane are relatively close to each other. This appears to agree with the molecular simulation results of Zhuravlev and Siepmann 
(1997), who determined that the critical point of squalane agreed more closely with that of tetracosane (i.e., the "backbone" of squalane) than with triacontane (an $n$ - $\mathrm{C}_{30}$ paraffin).

The P-T projection of Figure 8 can also be used to further examine the effect of functional groups on the phase behavior of $\mathrm{C}_{16}$ backbone molecules. Note how the critical

curves for hexane + hexadecane and hexane +1 -hexadecene are nearly identical (thus, the effect of the double bond is negligible), while the critical curve for hexane + 1hexadecanol extends to substantially higher pressures. Thus, the presence of the hydroxyl group significantly affects system phase behavior.

\section{Task 1c. Design and Construction of New Apparatus}

During the course of this project, it became clear that extending the experimental measurements to waxes longer than $\mathrm{C}_{36}$ could not be justified for several reasons. One, the interesting results obtained with waxes up to $\mathrm{C}_{36}$ took up a larger share of our time than was originally planned. Two, even with cost-sharing by Clemson University being significantly greater than was originally proposed, project funds were simply inadequate for building the relatively complex apparatus required for measuring systems containing waxes longer than $\mathrm{C}_{36}$. Three, even if funds had been available to build the apparatus, there would have been no time remaining in the grant period to perform the necessary measurements. Thus, Task 1c was not performed.

\section{Task 2a. Modeling VLE Data Using the Peng-Robinson Equation of State}

Conventional Peng-Robinson equation. An important objective of this research was to investigate the ability of a cubic equation of state to correlate and model the wax/solvent systems that had been measured. The Peng-Robinson (P-R) equation was chosen for this work and has the following form:

$$
P=\frac{R T}{v-b}-\frac{a(T)}{v(v+b)+b(v-b)}
$$

where the parameters $\mathrm{a}$ and $\mathrm{b}$ are calculated as shown below: 


$$
\begin{gathered}
\mathrm{a}=0.45724 \frac{\mathrm{R}^{2} \mathrm{~T}_{\mathrm{c}}^{2}}{\mathrm{P}_{\mathrm{c}}}\left(1+\kappa\left(1-\mathrm{T}_{\mathrm{r}}^{0.5}\right)\right)^{2} \\
\mathrm{~b}=0.07780 \frac{\mathrm{RT}_{\mathrm{c}}}{\mathrm{P}_{\mathrm{c}}}
\end{gathered}
$$

As can be seen from the equations above, pure component critical temperatures and critical pressures are required as input. The pure component $\kappa$ is determined by finding the single value of $\kappa$ that provides the best fit to pure component vapor pressure data. A program written by Hutchenson (1990) that uses the method known as maximum likelihood was used for this fitting procedure.

For hexane and hexadecane, the two critical properties were obtained from literature values; good vapor pressure data for calculating $\kappa$ was also readily available. For 1-hexadecene and 1-hexadecanol, no critical properties had been measured. Therefore, the correlations of Teja et al. (1990) and Gude et al. (1991) were used to estimate $\mathrm{T}_{\mathrm{c}}$ and $\mathrm{P}_{\mathrm{c}}$ for 1-hexadecanol and 1-hexadecene, respectively; it should be noted that several other correlations that were tested performed poorly. In the manner described above, values of $\kappa$ for 1-hexadecene and 1-hexadecanol were obtained by regressing vapor pressure data. For tetracosane and hexatriacontane, the critical properties are available in the literature (Ambrose and Tsonopoulos, 1995; Nikitin et al., 1997), and $\kappa$ was obtained from the regression of vapor pressure data. For tetracosane, the vapor pressure data of Morgan and Kobiyashi (1994) and API-42 (1966) were used. For hexatriacontane, the several sources of vapor pressure data were not in good agreement. The vapor pressure correlation available from Stephenson and Malanowski (1987) was used to calculate $\kappa$; justification for using this data source is given below.

After determining all pure component parameters, P-R is fit to the binary mixture equilibrium data by adjusting the single binary interaction parameter $\left(\mathrm{k}_{\mathrm{ij}}\right)$ that is contained in the mixing rules:

$$
\begin{gathered}
\mathrm{a}_{\text {mix }}=\sum_{\mathrm{i}} \sum_{\mathrm{j}} \mathrm{x}_{\mathrm{i}} \mathrm{x}_{\mathrm{j}} \mathrm{a}_{\mathrm{ij}} \\
\mathrm{a}_{\mathrm{ij}}=\sqrt{\mathrm{a}_{\mathrm{ii}} \mathrm{a}_{\mathrm{jj}}}\left(1-\mathrm{k}_{\mathrm{ij}}\right) \\
\mathrm{b}_{\text {mix }}=\sum_{\mathrm{i}} \mathrm{x}_{\mathrm{i}} \mathrm{b}_{\mathrm{i}}
\end{gathered}
$$

The optimized binary interaction parameter for each temperature was found by minimizing the following objective function: 


$$
\mathrm{OF}=\frac{\sum_{\mathrm{i}=1}^{\mathrm{n}}\left|\frac{\mathrm{x}_{\mathrm{i}}[\exp ]-\mathrm{x}_{\mathrm{i}}[\text { calc }]}{\mathrm{x}_{\mathrm{i}}[\exp ]}\right|+\sum_{\mathrm{i}=1}^{\mathrm{n}}\left|\frac{\mathrm{y}_{\mathrm{i}}[\exp ]-\mathrm{y}_{\mathrm{i}}[\text { calc }]}{\mathrm{y}_{\mathrm{i}}[\exp ]}\right|}{\mathrm{n}}
$$

where $\mathrm{n}$ is the number of experimental tie lines, and $\mathrm{x}_{\mathrm{i}}$ and $\mathrm{y}_{\mathrm{i}}$ are the mole fractions of the minor component in the liquid and vapor phases, respectively. It should be noted that the mixture critical point was not used in the objective function, because in many cases P-R underpredicts the mixture critical pressure. Thus, convergence is impossible at the actual measured critical pressure.

The Peng-Robinson equation was used to correlate the data obtained in our laboratory for binary mixtures of hexane with model F-T waxes having a $\mathrm{C}_{16}$ backbone. Table 11 shows the optimized binary interaction parameters and the average absolute percent deviation (AAPD) between the calculated and measured compositions for the mixtures for the minor component. The largest deviations in the liquid phase occur for those compositions approaching the vapor pressure of hexane and the mixture critical points, and are particularly large (i.e., up to 30\%) for the isotherms at 472 and 524 K. For the vapor phase, the deviations are largest at both the lowest temperatures (where the minor component solubility is very low) and at the highest temperatures. Visual comparison between experimental and calculated results is also shown in Figure 9. In summary, the P-R equation does an adequate job of fitting all of these systems; furthermore, the $\mathrm{k}_{\mathrm{ij}}$ 's are small and reasonably well behaved. Thus, one is able to predict phase compositions for the hexane $+\mathrm{C}_{16}$ wax systems with good confidence over a wide range of temperatures and pressures.

Table 11. Optimized binary interaction parameters for the P-R equation, and deviations between experimental and calculated results for the systems hexane + hexadecane, hexane +1 -hexadecene, and hexane + 1-hexadecanol.

\begin{tabular}{|c|c|c|c|c|c|c|c|}
\hline $\mathrm{T}(\mathrm{K})$ & Opt. $k_{i j}$ & AAPD in $x^{a}$ & AAPD in $y$ & $\mathrm{~T}(\mathrm{~K})$ & Opt. $k_{i j}$ & AAPD in $x^{a}$ & AAPD in $y$ \\
\hline \multicolumn{4}{|c|}{ hexane + hexadecane } & \multicolumn{4}{|c|}{ hexane + 1-hexadecanol } \\
\hline 472.3 & -0.01 & 8.3 & 2.8 & 472.1 & 0.02 & 8.6 & 4.8 \\
\hline 524.4 & 0.00 & 7.7 & 2.0 & 524.4 & 0.02 & 7.1 & 1.5 \\
\hline 572.5 & 0.00 & 5.2 & 4.9 & 572.4 & 0.03 & 1.6 & 2.6 \\
\hline 623.0 & 0.02 & 5.0 & 8.4 & 623.0 & 0.03 & 2.3 & 4.9 \\
\hline \multicolumn{4}{|c|}{ hexane +1 -hexadecene } & & \multicolumn{3}{|c|}{$\mathrm{n} \mid \mathrm{r}_{\text {[ound }} \mathrm{x}$ [olo } \\
\hline $\begin{array}{l}472.1 \\
5247\end{array}$ & $\begin{array}{l}0.00 \\
0.00\end{array}$ & $\begin{array}{l}9.6 \\
67\end{array}$ & $\begin{array}{l}2.9 \\
19\end{array}$ & & & $\sum_{i=1} \mid \frac{x_{i}[x p]-x_{i} l}{x_{i}[\exp ]}$ & \multirow{2}{*}{$\times 100 \%$} \\
\hline $\begin{array}{l}524.7 \\
572.5\end{array}$ & $\begin{array}{c}0.00 \\
-0.02\end{array}$ & $\begin{array}{l}6.7 \\
7.3\end{array}$ & $\begin{array}{l}1.9 \\
1.8\end{array}$ & & & $\mathrm{n}$ & \\
\hline
\end{tabular}


Unfortunately, modeling results for the hexane + tetracosane and hexane + hexatriacontane systems were not as encouraging. As shown in Table 12 (and also in Figure 10), large AAPD's between the experimental and calculated compositions (again, in terms of the minor component) were obtained with the optimized binary interaction parameters. For the hexane + tetracosane system, the fit to the data was adequate at the lower temperatures. However, as the temperature increased, the quality of the fit declined, particularly the liquid-phase composition fit. For hexane + hexatriacontane, the fit was poor at all temperatures. Furthermore, the $\mathrm{k}_{\mathrm{ij}}$ 's are large and vary widely; thus, they cannot be used for predicting phase compositions at other temperatures with any confidence.

Table 12. Optimized binary interaction parameters for the P-R equation, and deviations between experimental and calculated results for the systems hexane + tetracosane and hexane + hexatriacontane.

\begin{tabular}{|c|c|c|c|c|c|c|c|}
\hline $\mathrm{T}(\mathrm{K})$ & Opt. $\mathrm{k}_{\mathrm{ij}}$ & AAPD in $x^{a}$ & AAPD in $y$ & $\mathrm{~T}(\mathrm{~K})$ & Opt. $k_{i j}$ & AAPD in $x^{a}$ & AAPD in $y$ \\
\hline \multicolumn{4}{|c|}{ hexane + tetracosane } & \multicolumn{4}{|c|}{ hexane + hexatriacontane } \\
\hline 473.0 & -0.01 & $11.1 \%$ & $14.4 \%$ & 521.7 & -0.14 & $39.6 \%$ & $20.4 \%$ \\
\hline 524.3 & -0.04 & $11.0 \%$ & $7.5 \%$ & 573.1 & -0.24 & $42.7 \%$ & $25.6 \%$ \\
\hline 573.4 & -0.11 & $22.1 \%$ & $5.1 \%$ & 621.8 & 0.12 & $31.9 \%$ & $56.8 \%$ \\
\hline 622.9 & -0.20 & $33.0 \%$ & $2.2 \%$ & & & & \\
\hline $\mathrm{a}_{\mathrm{AA}}$ & $=\sum_{i=1}^{n} \mid x_{i}$ & $\frac{\mathrm{xp}]-\mathrm{x}_{\mathrm{i}}[\mathrm{calc}]}{\mathrm{x}_{\mathrm{i}}[\exp ]}$ & & & & & \\
\hline
\end{tabular}

In summary, then, the above results indicate that the conventional P-R equation is not capable of correlating phase compositions for binary mixtures of hexane with alkanes larger than $\mathrm{C}_{24}$. Modifications to P-R were made in an attempt to correct this problem, and are discussed below.

Modified Peng-Robinson equation. An obvious point, but one that is sometimes overlooked by researchers, is that an equation of state must first be capable of predicting pure component properties if there is to be any hope of fitting mixture data. Thus, as a first step in improving both the correlative and predictive ability of P-R, we used vapor pressure and liquid density data to determine "regressed" values of $\mathrm{T}_{c}, \mathrm{P}_{c}$, and $\kappa$.

Before regressing the Peng-Robinson parameters to liquid density and vapor pressure data, however, it was necessary to critically evaluate the data to be used in the regression. Of particular concern was the accuracy of data for the higher molecular weight wax compounds. For liquid densities, data over a wide range of temperatures and 
pressures are available from Doolittle (1964) up to a carbon chain length of 40. Other density data are available for even higher molecular weight alkanes (up to $\mathrm{C}_{94}$ ), but the measurements are limited to small temperature and pressure ranges. Fortunately, we have found that the methods given by Doolittle for extrapolating density data to higher molecular weight alkanes agree with experimental measurements from other sources. For example, extrapolation to calculate the density of $\mathrm{C}_{94}$ shows good agreement with experiment (see Table 13). Therefore, the method of Doolittle was used to calculate liquid densities for use in parameter regression when experimental values were not available.

Table 13. Comparison of experimental and calculated densities for $\mathrm{C}_{94}$.

\begin{tabular}{cccc}
\hline $\mathrm{T}\left({ }^{\circ} \mathrm{C}\right)$ & $\rho(\exp )$ & $\rho($ calc $)$ & $\%$ error \\
\hline 115 & 0.7833 & 0.7848 & -0.19 \\
125 & 0.7774 & 0.7796 & -0.28 \\
135 & 0.7714 & 0.7742 & -0.36 \\
\hline
\end{tabular}

As far as vapor pressures are concerned, few experimental data are available in the literature for alkanes larger than $\mathrm{C}_{36}$. Furthermore, vapor pressure data from multiple sources (i.e., to check the consistency of data) only exist for alkanes up to $\mathrm{C}_{28}$. Although the API-44 compilation lists vapor pressures for components up to $\mathrm{C}_{100}$, they are not actual experimental measurements, but extrapolations to long-chain alkanes from shortchain alkanes. Another sources for vapor pressure "data" is the handbook by Stephenson and Malanowski (1987). This source also has Antoine constants available up to $\mathrm{C}_{100}$, but it is unknown how these constants were determined. It is virtually certain, however, that for the higher molecular weight alkanes they are only extrapolated values.

To determine the best values for the vapor pressures of hexatriacontane, a comparison was made between the vapor pressures from the various sources to those determined by extrapolating our binary VLE data for hexane + hexatriacontane $\left(\mathrm{C}_{36}\right)$. Using an enhancement factor plot (Joyce and Thies, 1996), low-pressure vapor phase data from binary VLE were extrapolated to the pure wax component vapor pressure (i.e., where the natural log of the enhancement factor equals zero). As an example of this technique, Figure 11 shows how vapor pressure $\left(\mathrm{P}^{\text {sat }}\right)$ data obtained by this method agree closely with measured $\mathrm{P}^{\text {sat }}$ data for hexadecane. Similar agreement between measured and extrapolated $\mathrm{P}^{\text {sat, }}$ s was found for tetracosane and squalane. Therefore, to test the various $\mathrm{P}^{\text {sat }}$ data sources for $\mathrm{C}_{36}$, vapor pressures were obtained by extrapolation of the binary $\mathrm{C}_{6}$ 
$+\mathrm{C}_{36}$ VLE data. As can be seen in Figure 12, the vapor pressures from Stephenson and Malanowski agree most closely with our results. Thus, it was assumed that the Antoine constants from Stephenson and Malanowski best represent the actual vapor pressures of long-chain alkanes.

After obtaining the best set of liquid densities and vapor pressures as described above, a downhill simplex method was used to simultaneously regress the three P-R parameters of $T_{c}, P_{c}$, and $\kappa$ so as to obtain the best fit for each component. It should be noted that this method is identical to that used to obtain pure component parameters for modern equations of state such as PHCT and SAFT. Using the regressed critical properties and $\kappa$, good fits (i.e., within $\pm 3 \%$ ) to the data were obtained. Both the experimental (exp) and regressed (reg) properties are shown in Table 14 below. The regressed parameters are generally well-behaved functions of the alkane chain length. Even more encouraging, the parameters $\mathrm{a}_{\mathrm{c}}$ and $\mathrm{b}$ in $\mathrm{P}-\mathrm{R}$ are a linear function of molecular weight over the waxes tested thus far (see Figures 13 and 14). Clearly, such a trend, if it continues to hold for the higher molecular weight waxes, would have useful predictive value.

Table 14. Comparison of experimental and regressed critical properties.

\begin{tabular}{ccccccc}
\hline Component & $\mathrm{T}_{\mathrm{c}}(\exp )$ & $\mathrm{T}_{\mathrm{c}}(\mathrm{reg})$ & $\mathrm{P}_{\mathrm{c}}(\exp )$ & $\mathrm{P}_{\mathrm{c}}(\mathrm{reg})$ & $\kappa(\exp )$ & $\kappa(\mathrm{reg})$ \\
\hline Hexane & 507.5 & 510.0 & 30.25 & 31.11 & 0.8116 & 0.8315 \\
Hexadecane & 722.0 & 729.8 & 14.1 & 16.33 & 1.3704 & 1.3750 \\
Tetracosane & 800.0 & 829.8 & 8.7 & 12.89 & 1.7825 & 1.6736 \\
Octacosane & 824.0 & 861.1 & 7.44 & 11.38 & 1.9993 & 1.8201 \\
Hexatriacontane & 872.0 & 902.1 & 4.72 & 9.00 & 2.2511 & 2.1767 \\
\hline
\end{tabular}

With the improved fit of the "modified" P-R (m-PR) to pure component properties, the next test was to determine its ability to fit binary VLE data for the hexane + hexadecane, hexane + tetracosane, hexane + hexatriacontane, and hexane + squalane systems. As can be seen in Figure 15, good fits to both the liquid- and vapor-phase compositions were obtained for all systems. However, no improvement in the fit at the critical points was observed. This is not unexpected, as the parameters were not fit to the pure component critical points.

For hexane + hexadecane, a good fit to the experimental data is obtained by using a small, nearly constant interaction parameter (see Table 15). The table also indicates that m-PR gives a slightly better fit to the experimental data than the traditional P-R. For the 
more asymmetric systems (hexane + tetracosane, hexane + hexatriacontane, and hexane + squalane), m-PR is found to give a much improved fit to the data. However, the optimized binary interaction parameters are still relatively large and vary strongly with temperature, although to a lesser extent than by fitting the data by conventional means (compare to Table 12).

Table 15. Optimized binary interaction parameters for the m-PR equation, and deviations between experimental and calculated results for the systems hexane + hexadecane, hexane + tetracosane, hexane + hexatriacontane, and hexane + squalane.

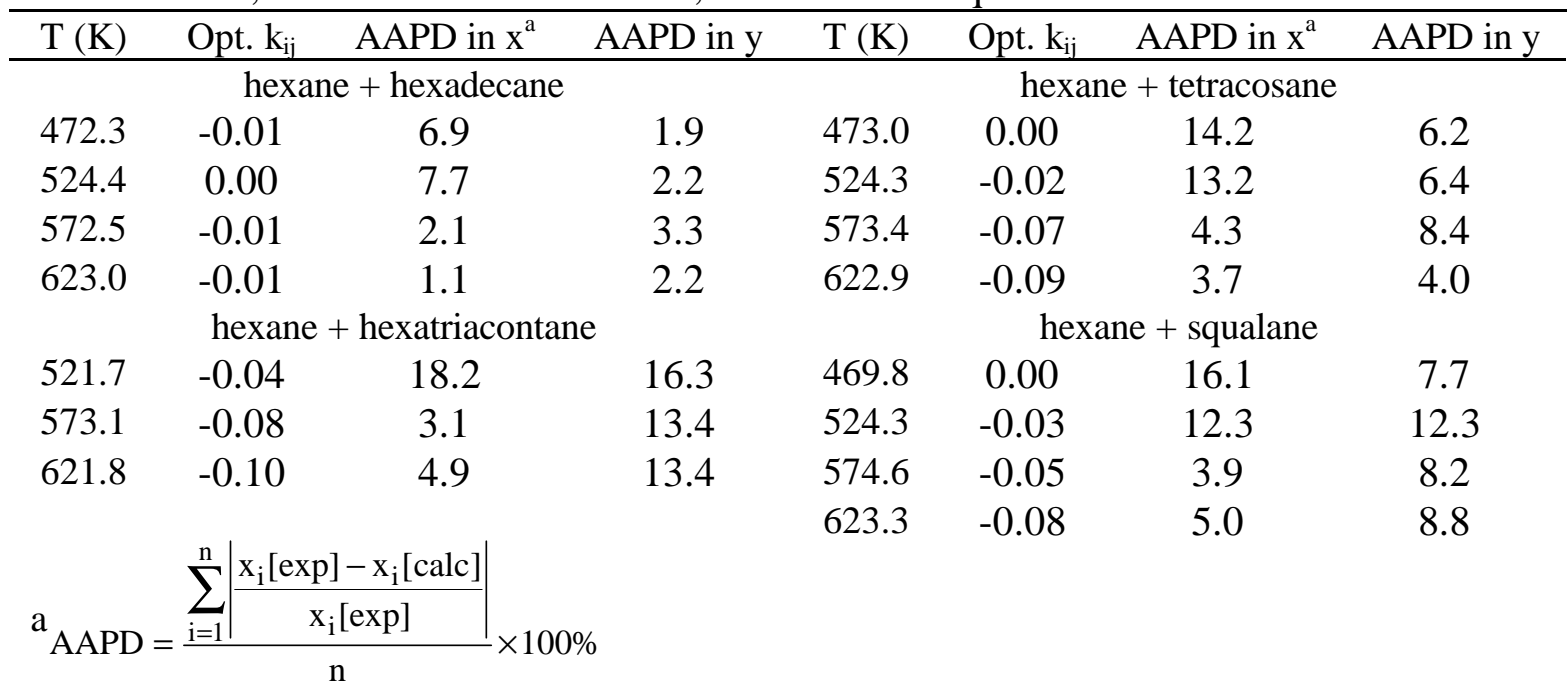

For any equation of state to have predictive value, the interaction parameters must change in a well-behaved manner. As shown in Figure 16, initial results indicate that when the solute is smaller than $\mathrm{C}_{20}$ in size, the interaction parameter is small $\left(\mathrm{k}_{\mathrm{ij}} \approx-0.01\right)$ and constant with respect to temperature and the size of the solvent. However, for systems where the solute is larger than $\mathrm{C}_{24}$, the $\mathrm{k}_{\mathrm{ij}}$ 's are larger and are also a function of temperature. As can be seen in Figure 17, $\mathrm{k}_{\mathrm{ij}}$ 's decrease with increasing reduced temperature. However, the limited data available still suggest that the size of the solvent is not important. More high-quality VLE data of the type measured in this study (i.e., that include comprehensive vapor- and liquid-phase measurements) are required to determine with more certainty what effect alkane length has on the optimized $\mathrm{k}_{\mathrm{ij}}$.

\section{Task 2b. Examination of SAFT Equation}

The Statistical Associated Fluid Theory (SAFT) equation of state is a modern 
equation that was developed from both statistical mechanics and computer simulation (Chapman et al., 1990; Huang and Radosz, 1990; 1991). SAFT has been claimed to be predictive for simple systems such as mixtures of alkanes. Thus, SAFT was used to model the $\mathrm{C}_{6}+\mathrm{C}_{16}, \mathrm{C}_{6}+\mathrm{C}_{24}$, and $\mathrm{C}_{6}+\mathrm{C}_{36}$ binaries. Interaction parameters were optimized as described previously. The optimized binary interaction parameters and the AAPD between the calculated and measured compositions are shown in Table 16. The interaction parameters were optimized using the same objective function as was used for P-R.

Table 16. Optimized binary interaction parameters for the SAFT equation, and deviations between experimental and calculated results for the systems hexane + hexadecane, hexane + tetracosane, and hexane + hexatriacontane.

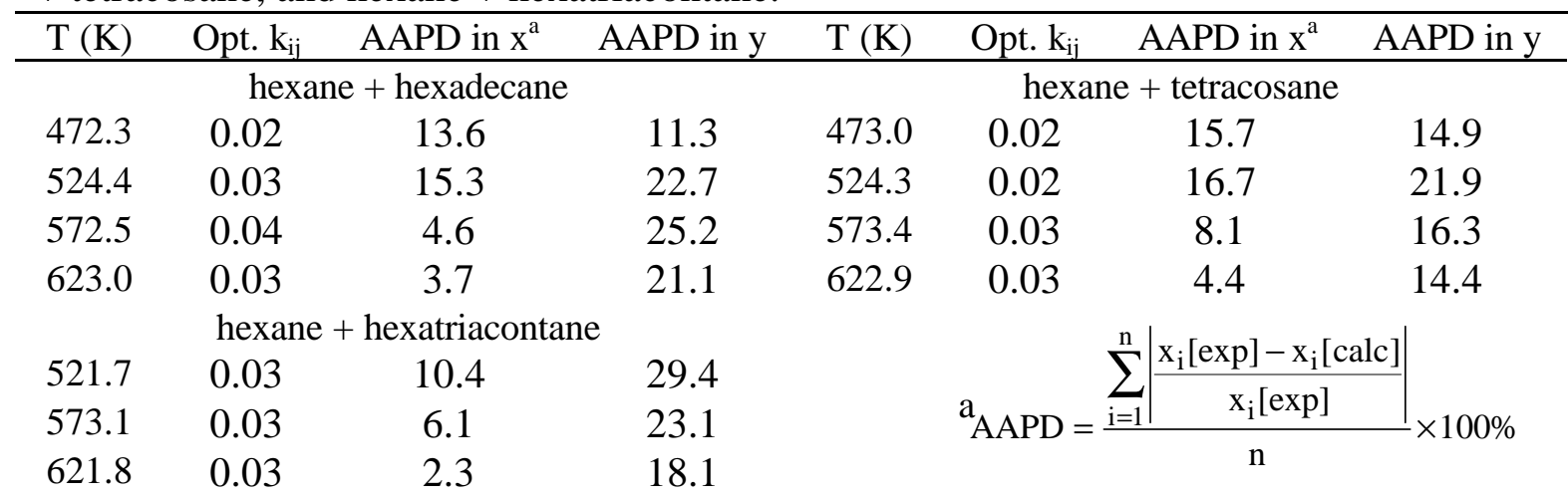

Calculated and experimental data are shown in Figure 18 for the liquid-and vaporphase compositions, respectively. As can be seen in the figures, SAFT fits the bubble curve well but consistently underpredicts the wax solubilities in the vapor phase and overpredicts the mixture critical points. However, the results in Table 16 indicate that a small, nearly constant $\mathrm{k}_{\mathrm{ij}}$ of $0.03 \pm 0.01$ was found to provide the best fit to all the systems at all measured temperatures. Furthermore, this is the same value for $\mathrm{k}_{\mathrm{ij}}$ obtained by Radosz (1998), who has recently shown that SAFT accurately predicts liquid-phase compositions for ethane + long alkane mixtures. These results provide compelling evidence that SAFT is indeed a predictive equation for determining liquid-phase compositions in mixtures of light gases and solvents with long alkanes up to at least $\mathrm{C}_{36}$.

Nevertheless, SAFT still has its problems too. For all the systems examined, SAFT significantly underpredicted vapor-phase wax solubility and overpredicted the observed mixture critical pressure. Thus, Chapman and co-workers at Rice University are working on revisions to SAFT. They have recently obtained improved fits to our 
experimental VLE data with SAFT by modifying the equation itself and by revising the method for developing SAFT pure component parameters (1998).

\section{Task 3a. Process Configuration Studies Using the ASPEN PLUS Simulation Package}

The Aspen Plus ${ }^{\mathrm{TM}}$ simulation package was used to perform process simulation studies for the proposed Fischer-Tropsch (F-T) process. The simulations studied the effects of several process parameters, including the solvent used, the ratio of solvent to non-solvent, the temperatures and pressures of the extraction, and others. The F-T wax examined was assumed to contain only alkanes and follow an Anderson-Schultz-Flory distribution with an $\alpha$ of 0.95 (which gives a wax that has a majority of its molecules with chain lengths between 1 and 100). For all the process simulation studies, the RedlichKwong-Soave (RKS) cubic equation of state was used, which gives very similar results to P-R. As with P-R, RKS was found to not accurately model the phase behavior of the systems of solvent + F-T waxes. However, although RKS cannot give accurate values for system equilibrium, it should in general give the proper trends (i.e., critical curves go through increasing maxima as asymmetry is increased, longer-chain alkanes have lower vapor-phase solubilities than shorter chains, etc.) for VLE calculations. Therefore, the simulations give results that are useful on a qualitative basis.

In order to use RKS, several pure component and mixture properties are needed for the calculation. However, experimental values of $T_{C}$ and $P_{c}$ were not available for $n$ paraffins above $\mathrm{C}_{36}$. The critical properties for molecules up to $\mathrm{C}_{100}$ were estimated using the method of Tsonopoulos and Tan (1993). Using the estimated critical properties, it was possible to calculate the acentric factor using the vapor pressures available in Stephenson and Malanowski. All molecules between $\mathrm{C}_{1}$ and $\mathrm{C}_{100}$ were treated as discreet components, no pseudocomponents were used. For all simulations, the binary interaction parameters $\left(\mathrm{k}_{\mathrm{ij}} \mathrm{s}\right)$ were set to zero (for lack of a better alternative).

A schematic of the ASPEN process is depicted in Figure 19. The process was modeled by a series of "Mixing Units" and "Flash2 Units". Mixing Units were used to calculate mass balances when two or more inlet streams combined to give one outlet stream, and Flash2 Units were used to perform flash calculations for inlet streams that phase split.

A Mixing Unit ("Reactor Mixing Unit”) and Flash2 Unit ("Reactor Flash2 Unit”) 
were used to model the slurry reactor. The F-T wax was fed continuously at a total rate of $1,000 \mathrm{kmol} / \mathrm{hr}$ (stream 1) to the Reactor Mixing Unit, where it combined with the recycled slurry (stream 6) from the "SCE (Supercritical Extraction) Flash2 Unit". The combined inlet stream from the Reactor Mixing Unit (2) was divided into a Vapor (3) and Liquid Product (4) using the Reactor Flash2 Unit. A temperature of $493 \mathrm{~K}$ and a total pressure of $10 \mathrm{~atm}$ were specified for the Reactor Flash2 Unit. These conditions are typical of those at which SBC F-T reactors operate.

The Extraction Unit was also modeled with a Mixing module (SCE Mixing Unit) and a Flash2 module (SCE Flash2 Unit). The Liquid Product from the Reactor Flash2 Unit (4) and a recycle stream (11) were combined in the SCE Mixing Unit. The effluent from this unit (5) was separated in SCE Flash2 Unit into a Light vapor phase (7) and a Heavy phase (6) that represents the unextracted products and the solid catalyst. The Light stream (7) from the SCE Flash2 Unit was sent to the recovery unit section.

In Recovery Flash2 Unit 1, the temperature and/or pressure were chosen to condense the heaviest products (8). Uncondensed light components from the Recovery Flash2 Unit 1 (9) were recycled to the extraction unit via the Recycle Mixing Unit. Additional recovery units were included in some runs. In this case, the condensed product (8) from Recovery Flash2 Unit 1 was sent to a Recovery Flash2 Unit 2, where additional solvent was vaporized and recycled to the Recycle Mixing Unit. When a third stage of recovery was included, the condensed product (14) from the Recovery Flash2 Unit 2 was sent to a third Recovery Flash2 Unit, and the solvent vaporized was again recycled to the Recycle Mixing Unit.

In all of the calculations, the solvent/non-solvent molar ratio entering the extraction unit, i.e., in Stream 5, was specified. The solvent/non-solvent molar ratio was defined as:

$$
\text { Ratio }=\mathrm{S} /(\mathrm{T}-\mathrm{S})
$$

where $\mathrm{S}$ is the molar flowrate of the specified solvent in stream $\mathbf{5}$ and $\mathrm{T}$ is the total molar flowrate of stream 5 .

\section{Process Parameters}

The net solvent requirement is a critical element of process feasibility. It is important that the amount of solvent lost from the process, i.e., the solvent remaining in 
the End Product stream $8\left(\mathrm{E}_{\mathrm{s}}\right)$, be less than the amount of solvent produced by the F-T reaction $\left(\mathrm{ASF}_{\mathrm{s}}\right)$ so that it will not be necessary to purchase solvent from an outside source. The ratio $\mathrm{E}_{\mathrm{s}} / \mathrm{ASFs}$ is used to determine if a net import of solvent is required, assuming that all of the solvent in the Vapor (3) is recovered.

High makeup flowrates indicate loss of solvent either in the Vapor leaving the reactor (stream 3) or in the End Product (e.g., stream 8). If the extraction conditions are such that large quantities of solvent are dissolved in the Slurry Recycle (6), there will be a large quantity of solvent in stream 3. This is detrimental, as recovery of this solvent would lead to a high energy requirement for separation and recompression. The amount of solvent in stream $\mathbf{8}$ is determined primarily by conditions in the recovery unit.

The ratio $\mathrm{V} / \mathrm{P}$ is defined as the total molar flowrate of the vapor stream entering the Extraction Unit (11) divided by the production rate $\mathrm{P}$ of stream $\mathbf{1}(1,000 \mathrm{kmol} / \mathrm{hr})$. It is a rough proxy for the size of the Extraction and Recovery Units, and for the energy required for solvent recovery, recycle and recompression. High V/P ratios are undesirable.

The ratio $\mathrm{L} / \mathrm{P}$ is defined as the total molar flowrate of the liquid slurry leaving the Reactor (4) divided by the production rate $(1,000 \mathrm{kmol} / \mathrm{hr})$. This ratio indicates how much slurry must be fed to the Extraction Unit in order to recover the entire product. High L/P values are undesirable since they suggest the need for a larger slurry pump, and more heat exchange area between the Reactor and the Extraction Unit.

A final consideration in evaluating process flowsheets was the average molecular weight (AMW) of the reactor slurry, that is, stream 4. A high AMW indicates a substantial recycle of heavy components back to the reactor, relative to recycle of lighter products, and suggests selective extraction of lighter products. If the AMW of the reactor slurry is too high, the resulting high viscosity of the slurry could cause undesirable effects in the reactor, such as low gas holdup, an unpumpable slurry, or mixture gelation.

\section{Retrograde Condensation}

A retrograde condensation region is a portion of the two-phase region where vapor quality is increased by raising pressure or dropping temperature. To help in the description of retrograde behavior, Figure 20 shows a constant-composition PT phase diagram for a 20/1 molar ratio of $n$-pentane to the F-T product. The mixture critical point 
lies close to the solvent critical point because the mixture contains such a large quantity of solvent. In addition, the two-phase pressure maximum lies on the dew point curve. Figure 20 shows three contours of constant molar vapor fraction. The locus of the pressure maxima for the curves of constant molar vapor fraction forms the boundary of the temperature-retrograde region. Moving from point 1 to point 4 in Figure 20 illustrates the phase behavior associated with the temperature-retrograde region. At point 1 , the temperature and pressure are such that the system is one phase. As temperature is increased isobarically, the system enters the two-phase region by crossing the dew line and entering the retrograde region (point 2). Within the temperature-retrograde region, an increase in temperature causes additional liquid to condense. As the mixture is heated further from point 2 to point 3, increasing temperature causes vaporization after the retrograde boundary is crossed. Continuing from point 3 to point 4 , the dew line is crossed again and the mixture is completely vaporized.

Product recovery through isobaric heating is of special interest because recompression of the recycled solvent vapor (9) can be eliminated or minimized. However, Figure 20 raises some question about the feasibility of employing temperatureretrograde condensation for product recovery. First, the temperature-retrograde region is narrow with respect to temperature (maximum width $\sim 25 \mathrm{~K}$ ). Second, unless the pressure is very close to the mixture critical point, the extent of condensation is very limited. Those features suggest that a large solvent recycle stream and a high V/P ratio will be required in temperature-retrograde operation.

A region of pressure-retrograde behavior is also shown in Figure 20. At pressures above the lower boundary of this region, decreasing the pressure causes liquid to condense and increasing the pressure causes vaporization. The pressure-retrograde region is substantially larger than the temperature-retrograde region, and a substantial portion of the two-phase region above the mixture critical pressure is in the pressure-retrograde region.

\section{Process Simulations}

Temperature-Retrograde Condensation Simulations. For this group of process simulations, condensation in the Recovery Unit was achieved by isobarically raising the temperature of the light stream (7) leaving the Extraction Unit. For $n$-pentane, $n$-hexane, 
and $n$-heptane, feasible designs based on temperature-retrograde condensation were developed at a 20:1 solvent/non-solvent molar ratio for extraction and recovery pressures in the range of 50-60 atm, 40-50 atm, and 35-40 atm, respectively. Extraction temperatures varied between 515 - $530 \mathrm{~K}, 535$ - $580 \mathrm{~K}$, and 570 - $600 \mathrm{~K}$ for $n$-pentane, $n$ hexane, and $n$-heptane, respectively.

Table 17 compares process performance for five temperature-retrograde simulations with $n$-pentane, where only the recovery temperature was varied. As recovery temperature increased from $525 \mathrm{~K}$, the Makeup, V/P ratio, and L/P ratio decreased and went through minima at about $570 \mathrm{~K}$. However, the increase in Makeup between 570 and $580 \mathrm{~K}$ suggests that the latter temperature may be somewhat outside the region in which temperature-retrograde condensation occurs. The $\mathrm{AMW}$ and $\mathrm{E}_{\mathrm{s}} / \mathrm{ASF}_{\mathrm{s}}$ ratio decreased with increasing recovery temperature, but did not go through a minimum. Since $\mathrm{ASF}_{\mathrm{s}}$ is $40.7 \mathrm{kmol} / \mathrm{h}$ for $n$-pentane, the values of $\mathrm{E}_{\mathrm{s}} / \mathrm{AFS}_{\mathrm{s}}$ show that the majority of the Makeup requirement results from dissolution of the solvent into the liquid stream that is recycled to the reactor, followed by vaporization from the reactor.

Table 17. The effect of recovery temperature on process performance using temperatureretrograde product recovery. Solvent: $n$-pentane; solvent/non-solvent ratio $=20$.

\begin{tabular}{|c|c|c|c|c|c|c|c|c|}
\hline \multicolumn{2}{|c|}{ Extraction Cond. } & \multicolumn{2}{|c|}{ Recovery Cond. } & \multicolumn{5}{|c|}{ Calculated Process Parameters } \\
\hline $\begin{array}{l}\text { Pext } \\
\text { (atm) }\end{array}$ & $\begin{array}{l}\mathrm{T}_{\text {ext }} \\
(\mathrm{K})\end{array}$ & $\begin{array}{l}\text { Prec } \\
\text { (atm) }\end{array}$ & $\begin{array}{l}\mathrm{T}_{\text {rec }} \\
(\mathrm{K})\end{array}$ & $\begin{array}{c}\text { Makeup } \\
(\mathrm{kmol} / \mathrm{hr})\end{array}$ & AMW & $\mathrm{L} / \mathrm{P}$ & $\mathrm{V} / \mathrm{P}$ & $\mathrm{E}_{\mathrm{S}} / \mathrm{ASF}_{\mathrm{S}}$ \\
\hline 60 & 520 & 60 & 525 & 207,000 & 446 & 25.1 & 392 & 78 \\
\hline 60 & 520 & 60 & 540 & 59,600 & 420 & 7.3 & 119 & 62 \\
\hline 60 & 520 & 60 & 560 & 40,600 & 395 & 4.8 & 80 & 43 \\
\hline 60 & 520 & 60 & 570 & 37,900 & 381 & 4.2 & 70 & 36 \\
\hline 60 & 520 & 60 & 580 & 41,100 & 375 & 4.3 & 71 & 31 \\
\hline
\end{tabular}

Three solvents, $n$-pentane, $n$-hexane, and $n$-heptane, are compared in Table 18 under conditions where temperature-retrograde condensation was used for product recovery. This table shows the process parameters for the designs with the lowest required Makeup for each solvent. For $n$-pentane, the pressure and temperature ranges of the Extraction and Recovery Units approximates the temperature retrograde region shown in Figure 20, although the difference between the extraction and recovery temperatures $(\sim 50 \mathrm{~K})$ is considerably greater than the width of the retrograde condensation region in Figure 20. This may be the result of the broader range of compounds that are present in the light phase entering the Recovery Unit, and the different composition of the heavy 
product in the converged process simulation. The difference in temperature between the Extraction and Recovery Units were smaller for $n$-hexane and $n$-heptane, $27 \mathrm{~K}$ and $10 \mathrm{~K}$, respectively. At a 20:1 solvent/non-solvent ratio, increasing solvent size reduced the temperature retrograde region.

Finally, it should be noted that the AMW of the reactor slurry (stream 4) with heptane solvent is less than that of the product produced in the reactor (stream 1); for hexane solvent, it increases only slightly. Thus, for these two cases no buildup of heavy waxes in the reactor (and the accompanying problems with high viscosities) will occur.

Table 18. Process parameters for temperature-retrograde product recovery at the lowest Makeup determined for each solvent. Solvent/non-solvent ratio $=20$.

\begin{tabular}{cccccccccc}
\hline & \multicolumn{3}{c}{ Extraction Cond } & \multicolumn{3}{c}{ Recovery Cond. } & \multicolumn{5}{c}{ Calculated Process Parameters } \\
Solvent & $\begin{array}{c}\mathrm{P}_{\text {ext }} \\
(\mathrm{atm})\end{array}$ & $\begin{array}{c}\mathrm{T}_{\text {ext }} \\
(\mathrm{K})\end{array}$ & $\begin{array}{c}\mathrm{P}_{\mathrm{rec}} \\
(\mathrm{atm})\end{array}$ & $\begin{array}{c}\mathrm{T}_{\mathrm{rec}} \\
(\mathrm{K})\end{array}$ & $\begin{array}{c}\text { Makeup } \\
(\mathrm{kmol} / \mathrm{hr}\end{array}$ & AMW & $\mathrm{L} / \mathrm{P}$ & $\mathrm{V} / \mathrm{P}$ & $\mathrm{E}_{\mathrm{s}} / \mathrm{ASF}_{\mathrm{s}}$ \\
\hline pentane & 60 & 520 & 60 & 570 & 37,900 & 381 & 4 & 70 & 36 \\
hexane & 50 & 570 & 50 & 597 & 60,700 & 316 & 14 & 228 & 41 \\
heptane & 40 & 590 & 40 & 600 & 68,600 & 222 & 27 & 228 & 73 \\
\hline
\end{tabular}

Pressure-Retrograde Condensation Simulations. For this portion of the study, product was recovered by pressure reductions using isothermal operation of the Extraction and Recovery units. Various extraction temperatures and pressures were studied using $n$ pentane, $n$-hexane, and $n$-heptane as solvents. Solvent/non-solvent molar ratios were 20:1 for all three solvents.

Typical results for pressure-retrograde condensation simulations with $n$-pentane are shown in Table 19. The extraction/recovery temperature varied between 515 to 580 $\mathrm{K}$, at otherwise constant conditions. This table shows that the Makeup and the AMW went through maxima at $540 \mathrm{~K}$. The maxima in the makeup flowrate and the AMW may be the result of a recovery pressure that is below the lower pressure retrograde boundary, especially at intermediate temperatures.

Table 19. The effect of extraction temperature on process performance using pressureretrograde product recovery. Solvent: $n$-pentane; solvent/non-solvent ratio $=20$.

\begin{tabular}{|c|c|c|c|c|c|c|c|c|}
\hline \multicolumn{2}{|c|}{ Extraction Cond. } & \multicolumn{2}{|c|}{ Recovery Cond. } & \multicolumn{5}{|c|}{ Calculated Process Parameters } \\
\hline $\begin{array}{l}P_{\text {ext }} \\
\text { (atm) }\end{array}$ & $\begin{array}{l}\mathrm{T}_{\text {ext }} \\
(\mathrm{K})\end{array}$ & $\begin{array}{l}\text { Prec } \\
\text { (atm) }\end{array}$ & $\begin{array}{l}\mathrm{T}_{\text {rec }} \\
(\mathrm{K})\end{array}$ & $\begin{array}{l}\text { Makeup } \\
(\mathrm{kmol} / \mathrm{hr})\end{array}$ & AMW & $\mathrm{L} / \mathrm{P}$ & $\mathrm{V} / \mathrm{P}$ & $\mathrm{E}_{\mathrm{S}} / \mathrm{ASF}_{\mathrm{S}}$ \\
\hline 60 & 515 & 40 & 515 & 46,600 & 509 & 6.5 & 96 & 40 \\
\hline
\end{tabular}




\begin{tabular}{lllllllll}
60 & 525 & 40 & 525 & 70,200 & 590 & 15.3 & 233 & 30 \\
60 & 540 & 40 & 540 & 90,100 & 612 & 29.0 & 453 & 22 \\
60 & 550 & 40 & 550 & 86,100 & 603 & 33.6 & 541 & 19 \\
60 & 560 & 40 & 560 & 72,200 & 584 & 33.2 & 563 & 17 \\
60 & 580 & 40 & 580 & 34,400 & 524 & 20.7 & 456 & 15 \\
\hline
\end{tabular}

The effect of recovery pressure was studied using $n$-hexane as solvent. Table 20 shows that Makeup, $\mathrm{L} / \mathrm{P}$ ratio, $\mathrm{V} / \mathrm{P}$ ratio and $\mathrm{E}_{\mathrm{S}} / \mathrm{ASF}_{\mathrm{S}}$ ratio all decreased with decreasing recovery pressure. In fact, the Makeup at the lowest recovery pressure, 37 atm, is the lowest observed in any of the pressure-retrograde simulations. Below $37 \mathrm{~atm}$, the simulation did not converge because there was no heavy phase leaving the Extraction Unit. This condition is referred to as "overextraction".

Table 20. The effect of recovery pressure on process performance using pressureretrograde product recovery. Solvent: $n$-hexane; solvent/non-solvent ratio $=20$.

\begin{tabular}{|c|c|c|c|c|c|c|c|c|}
\hline \multicolumn{2}{|c|}{ Extraction Cond. } & \multicolumn{2}{|c|}{ Recovery Cond. } & \multicolumn{5}{|c|}{ Calculated Process Parameters } \\
\hline $\begin{array}{l}\text { Pext } \\
\text { (atm) }\end{array}$ & $\begin{array}{l}\mathrm{T}_{\text {ext }} \\
(\mathrm{K})\end{array}$ & $\begin{array}{l}\text { Prec } \\
(\mathrm{atm})\end{array}$ & $\begin{array}{l}\mathrm{T}_{\mathrm{rec}} \\
(\mathrm{K})\end{array}$ & $\begin{array}{c}\text { Makeup } \\
(\mathrm{kmol} / \mathrm{hr})\end{array}$ & AMW & $\mathrm{L} / \mathrm{P}$ & $\mathrm{V} / \mathrm{P}$ & $\mathrm{E}_{\mathrm{S}} / \mathrm{ASF}_{\mathrm{S}}$ \\
\hline 50 & 570 & 36 & 570 & \multicolumn{5}{|c|}{ Overextraction } \\
\hline 50 & 570 & 37 & 570 & 13,900 & 355 & 4.9 & 95 & 43 \\
\hline 50 & 570 & 40 & 570 & 16,400 & 352 & 5.4 & 99 & 49 \\
\hline 50 & 570 & 43 & 570 & 20,700 & 345 & 6.2 & 110 & 60 \\
\hline 50 & 570 & 45 & 570 & 28,500 & 343 & 8.1 & 134 & 66 \\
\hline
\end{tabular}

In general, the Makeup flow rates for the pressure-retrograde simulations were lower than the temperature-retrograde designs. However, the lowest V/P and L/P ratios are similar for the two modes of product recovery. Moreover, the major energy requirements associated with pressure-retrograde and temperature-retrograde operation are roughly comparable. For example, with the $n$-hexane design in Table 20 at $\mathrm{P}_{\text {rec }}=37$ atm, 81,100 kmol/hr of vapor must be recompressed by $13 \mathrm{~atm}$ (stream 9 in Figure 3). In addition, the Makeup of 13,900 kmol/hr (stream 10 in Figure 3) must be recompressed by about $40 \mathrm{~atm}$, from the reactor pressure $(10 \mathrm{~atm})$ to the pressure of the Extraction Unit (50 atm). In comparison, the temperature-retrograde run with $n$-hexane that had the lowest Makeup (Table 18) would require heating about 170,000 kmol/hr by $27 \mathrm{~K}$ between the Extraction and Recovery Units, and the Makeup of approximately $61,000 \mathrm{kmol} / \mathrm{hr}$ be recompressed from approximately $10 \mathrm{~atm}$ to $50 \mathrm{~atm}$. The total compression requirement for the temperature-retrograde design, $2.4 \times 10^{6} \mathrm{kmol}-\mathrm{atm} / \mathrm{hr}$, is comparable to that of the pressure-retrograde design, $1.6 \times 10^{6} \mathrm{kmol}-\mathrm{atm} / \mathrm{hr}$, considering that neither design is 
optimized.

Low Solvent/Non-solvent Ratio Simulations. Simulations also were performed at low solvent/non-solvent molar ratios. Table 21 contains the parameters for the designs with the lowest Makeups for each solvent: $n$-pentane, $n$-hexane, $n$-heptane, and $n$-octane. Product recovery was accomplished by a combination of pressure-retrograde condensation and temperature reduction. With all four solvents, the makeup flowrates were significantly lower than the Makeups obtained in the retrograde-condensation regions, where higher solvent/non-solvent ratios were used. Furthermore, for all solvents but pentane, little or no buildup of the AMW in the reactor slurry (stream 4) occurred. However, the $\mathrm{E}_{\mathrm{S}} / \mathrm{ASF}_{\mathrm{S}}$ ratios were still greater than 1 in all four cases.

Table 21. Process parameters for low solvent/non-solvent ratio runs with the lowest makeup flow rates.

\begin{tabular}{|c|c|c|c|c|c|c|c|c|c|c|}
\hline \multirow[b]{2}{*}{ Solvent } & \multicolumn{3}{|c|}{ Extraction Cond } & \multicolumn{2}{|c|}{ Recovery Cond } & \multicolumn{5}{|c|}{ Calculated Process Parameters } \\
\hline & $\begin{array}{l}\text { Pext } \\
\text { (atm) }\end{array}$ & $\begin{array}{c}\mathrm{T}_{\text {ext }} \\
(\mathrm{K})\end{array}$ & Ratio $^{a}$ & $\begin{array}{l}\text { Prec } \\
\text { (atm) }\end{array}$ & $\begin{array}{l}\mathrm{T}_{\mathrm{rec}} \\
(\mathrm{K})\end{array}$ & $\begin{array}{c}\text { Makeup } \\
(\mathrm{kmol} / \mathrm{hr} \\
)\end{array}$ & AMW & $\mathrm{L} / \mathrm{P}$ & V/P & $\mathrm{E}_{\mathrm{S}} / \mathrm{ASF}_{\mathrm{S}}$ \\
\hline pentane & 34 & 680 & 3.1 & 31 & 630 & 4,250 & 504 & 30 & 136 & 9.2 \\
\hline hexane & 38 & 670 & 3.0 & 38 & 650 & 5,840 & 349 & 43 & 109 & 18 \\
\hline heptane & 36 & 650 & 3.0 & 30 & 630 & 1,660 & 269 & 35 & 156 & 23 \\
\hline octane & 40 & 650 & 3.35 & 30 & 630 & 1,750 & 199 & 12 & 34 & 41 \\
\hline$a_{\text {solvent }}$ & on-soly & ratio & & & & & & & & \\
\hline
\end{tabular}

Table 22 shows the parameters for four $n$-heptane designs with extraction pressures ranging from $35 \mathrm{~atm}$ to $42 \mathrm{~atm}$, with all other conditions constant. As extraction pressure was decreased, the Makeup decreased. The AMW and the $\mathrm{E}_{\mathrm{S}} / \mathrm{ASF}_{\mathrm{S}}$ ratio did not change significantly over the range of extraction pressures studied. Since $\mathrm{ASF}_{\mathrm{s}}$ for $n$-heptane is about $37 \mathrm{kmol} / \mathrm{hr}$, approximately half of the required Makeup for the design at $36 \mathrm{~atm}$ results from solvent in the product stream. The V/P ratio went through a flat minimum with extraction pressure, but the L/P ratio decreased significantly with decreasing pressure.

The results of the low solvent/non-solvent simulations are interesting because of the low makeup flowrates that are required. The Makeups were as low as 1.7 times the production rate, and a V/P ratio as low as 34 was achieved. The compression requirement for the $n$-hexane design in Table 21 is only about $1.6 \times 10^{5} \mathrm{kmol}-\mathrm{atm} / \mathrm{hr}$, roughly a factor of 10 lower than for the best runs at high solvent/non-solvent ratios. A potential problem 
with the low solvent/non-solvent region is the high operating temperatures of the Extraction Unit $(650-680 \mathrm{~K})$ that appear to be required. These high temperatures might cause deactivation of the F-T catalyst.

Table 22. The effect of extraction pressure on process performance for designs with low solvent/non-solvent ratios. Solvent: $n$-heptane; solvent/non-solvent ratio $=3$.

\begin{tabular}{|c|c|c|c|c|c|c|c|c|}
\hline \multicolumn{2}{|c|}{ Extraction Cond } & \multicolumn{2}{|c|}{ Recovery Cond } & \multicolumn{5}{|c|}{ Calculated Process Parameters } \\
\hline $\begin{array}{l}\text { Pext } \\
\text { (atm) }\end{array}$ & $\begin{array}{l}\mathrm{T}_{\text {ext }} \\
(\mathrm{K})\end{array}$ & $\begin{array}{l}\text { Prec } \\
\text { (atm) }\end{array}$ & $\begin{array}{l}\mathrm{T}_{\mathrm{rec}} \\
(\mathrm{K})\end{array}$ & $\begin{array}{l}\text { Makeup } \\
(\mathrm{kmol} / \mathrm{hr})\end{array}$ & AMW & $\mathrm{L} / \mathrm{P}$ & $\mathrm{V} / \mathrm{P}$ & $\mathrm{E}_{\mathrm{S}} / \mathrm{ASF}_{\mathrm{S}}$ \\
\hline 35 & 650 & 30 & 630 & \multicolumn{5}{|c|}{ Overextraction } \\
\hline 36 & 650 & 30 & 630 & 1,660 & 269 & 35 & 156 & 22 \\
\hline 38 & 650 & 30 & 630 & 2,600 & 253 & 65 & 109 & 24 \\
\hline 40 & 650 & 30 & 630 & 6,940 & 243 & 135 & 83 & 24 \\
\hline 41 & 650 & 30 & 630 & 25,700 & 254 & 294 & 99 & 22 \\
\hline 42 & 650 & 30 & 630 & \multicolumn{5}{|c|}{ Underextraction } \\
\hline
\end{tabular}

Staged Recovery Units. Since an $\mathrm{E}_{\mathrm{S}} / \mathrm{ASF}_{\mathrm{S}}$ ratio of less than one was not achieved with a single Recovery Unit, simulations were carried out with multiple Recovery Units to establish the feasibility of reducing the $\mathrm{E}_{\mathrm{S}} / \mathrm{ASF}_{\mathrm{S}}$ ratio to less than one, and to explore the influence of multiple Recovery Units on overall system behavior. Table 23 shows the effect of adding additional Recovery Units in series (see Figure 19) with the operating conditions of the SCE Units and the first Recovery Unit held constant. With a second Recovery Unit, operating at a marginally lower pressure than the first Recovery Unit (32 atm versus $34 \mathrm{~atm}$ ), the $\mathrm{E}_{\mathrm{S}} / \mathrm{ASF}_{\mathrm{S}}$ ratio decreased from 9.1 to 8.4, and the makeup flowrate decreased about $2.5 \%$. Reducing the pressure in the second recovery unit to 20 atm led to overextraction in the SCE Units. By reducing the solvent/non-solvent ratio to 2, it was possible to continue evaluating the second Recovery Unit. The $\mathrm{E}_{\mathrm{S}} / \mathrm{ASF}_{\mathrm{S}}$ ratio decreased to about 4, but the Makeup increased by about a factor of three. This increase was caused by increased dissolution of $n$-pentane into the liquid leaving the Extraction Unit. Reducing the pressure in the second Recovery Unit to $10 \mathrm{~atm}$ reduced the $\mathrm{E}_{\mathrm{S}} / \mathrm{ASF}_{\mathrm{S}}$ ratio to about 1.7 and had very little effect on the makeup flowrate.

Simulation results using a third extraction unit led to an $\mathrm{E}_{\mathrm{s}} / \mathrm{ASF}_{\mathrm{s}}$ ratio of 0.7. This demonstrates that the $\mathrm{E}_{\mathrm{S}} / \mathrm{ASF}_{\mathrm{S}}$ ratio can be reduced to less than one. However, the calculations in Table 23 also show that the operation of a system of Recovery Units can cause changes in the performance of the overall process, and require adjustment of the operating conditions. Further studies are required to understand how multiple recovery units can be best utilized. 
Table 23. Effect of additional product recovery units on process performance. Extraction temperature $=680 \mathrm{~K}$; Pressure $=34 \mathrm{~atm}$; solvent $=n$-pentane .

\begin{tabular}{cccccccccc}
\hline $\begin{array}{c}\text { Number } \\
\text { Recovery }\end{array}$ & \multicolumn{2}{c}{ Recovery 1 } & \multicolumn{2}{c}{ Recovery 2 } & \multicolumn{2}{c}{ Recovery 3 } & \multicolumn{2}{c}{ Solvent/ } & \multicolumn{2}{c}{ Solvent } \\
Units & $\mathrm{T}$ & $\mathrm{P}$ & $\mathrm{T}$ & $\mathrm{P}$ & $\mathrm{T}$ & $\mathrm{P}$ & Non-Solvent & Makeup & $\mathrm{E}_{\mathrm{s}} / \mathrm{ASF}_{\mathrm{s}}$ \\
& $(\mathrm{K})$ & $(\mathrm{atm})$ & $(\mathrm{K})$ & $(\mathrm{atm})$ & $(\mathrm{K})$ & $(\mathrm{atm})$ & Ratio & & \\
\hline 1 & 650 & 34 & --- & --- & --- & --- & 3 & 8,000 & 9.1 \\
\hline 2 & 650 & 34 & 650 & 32 & --- & --- & 3 & 7,800 & 8.4 \\
2 & 650 & 34 & 650 & 20 & --- & --- & 3 & \multicolumn{2}{c}{ Overextraction } \\
2 & 650 & 34 & 650 & 20 & --- & --- & 2 & 23,500 & 4.0 \\
2 & 650 & 34 & 650 & 10 & --- & --- & 2 & 22,600 & 1.7 \\
\hline 3 & 650 & 34 & 650 & 20 & 650 & 5 & 2 & 21,800 & 0.7 \\
\hline
\end{tabular}

\section{Conclusions}

Vapor and liquid equilibrium compositions have been measured for binary mixtures of hexane with hexadecane, 1-hexadecene, 1-hexadecanol, tetracosane, hexatriacontane, and squalane at temperatures from 472 to $623.0 \mathrm{~K}$ using a continuous-flow apparatus. Using a flow apparatus, it was possible to accurately measure compositions over a range of five orders of magnitude. Furthermore, little or no sample decomposition was observed in the systems containing long-chain alkanes. Some oligomerization occurred during experiments involving 1-hexadecene, but the amount was small and easily compensated for. VLE experiments at the elevated temperatures (up to $623 \mathrm{~K}$ ) we examined would have been impossible in a static apparatus because of the extended residence times required to reach equilibrium.

For all the systems examined, Type I phase behavior was observed. Type I phase behavior is defined as a system exhibiting only vapor-liquid equilbirium (VLE), with a continuous curve of vapor-liquid mixture critical points connecting the pure component critical points. No complex phase behavior, such as liquid-liquid equilibrium, was observed. As expected, the vapor-liquid critical curves run through a pressure maximum, and as the system asymmetry increased the maximum pressure of the critical curve increased.

Part of the goal of the experimental measurements was to evaluate the effect of the types of molecules present in a F-T wax, such as long-chain alkenes and alcohols and branched alkanes. Measurements for hexane + hexadecane were compared to the results of hexane +1 -hexadecene and hexane +1 -hexadecanol systems to determine the effect of the functional groups in long-chain molecules. Results indicate that the hydroxyl group does effect phase behavior for F-T waxes that are 16 carbons long, with 1-hexadecanol 
showing a significantly lower solubility in the vapor phase and a two-phase region that extends to substantially high pressures. For 1-hexadecene, the effect of the double bond is negligible. For the branched molecule, results appear to indicate that the phase behavior of squalane in hexane behaves more similarly to tetracosane (the backbone of squalane) than to the n-alkane with the same molecular weight as squalane (triacontane). However, it does not appear that the effect of the branched molecule can be assumed to behave identically to either tetracosane or triacontane. In summary, experiments indicate that in modeling of the Fischer-Tropsch process, it will be possible to assume the alkene components behave identically to alkanes of the same chain length, while it will be necessary to explicitly account for branched alkanes and long-chain alcohol molecules.

A cubic equation of state, Peng-Robinson, was used to correlate the experimental measurements of hexane with model wax components. P-R was found to accurately represent the phase behavior of the $\mathrm{C}_{16}$ model waxes using a small interaction parameter. Unfortunately, P-R poorly represented the phase behavior of the hexane + tetracosane and hexane + hexatriacontane systems. Also, the interaction parameters for these two systems were large and showed no discernible trend with system parameters. In its present form, P-R cannot give more than qualitative results in modeling the Fischer-Tropsch process.

Continuing examination of the cubic equation of state showed that P-R poorly represented the pure component liquid densities of the long-chain alkane systems, becoming worse as the n-alkane molecular weight increased. This could at least partially explain the poor fit of P-R to the hexane + tetracosane and hexane + hexatriacontane systems, as the equation of state cannot be expected to predict the binary system when it does not properly represent the pure component properties. Thus, P-R was modified by fitting its three pure component parameters to pure component vapor pressures and liquid densities. The regressed parameters $\mathrm{a}_{\mathrm{c}}$ and $\mathrm{b}$ from the modified Peng-Robinson equation (m-PR) were found to be linear functions of molecular weight. This is an important result, as it may be possible to extend m-PR to long-chain n-alkanes when no pure component information is available (as is possible with SAFT). Using these new parameters, substantial improvement was found in the correlation of the vapor- and liquid-phase compositions for systems with long-chain alkanes. m-PR poorly represented the mixture critical points, but that is not surprising considering the fact that the equation is no longer fit to the pure component critical point of the heavy component. Unfortunately, a 
relatively large interaction parameter was required to fit the mixture data. Initial results suggest it may be possible to estimate the interaction parameters from system properties, but more data are required to reach definitive conclusions on this matter.

The SAFT equation was used to model the systems of hexane with hexadecane, tetracosane, and hexatriacontane. SAFT fits the bubble curves well but consistently underpredicts the wax solubilities in the vapor phase and overpredicts the mixture critical points. Results have further shown that a small, nearly constant interaction parameter was found to provide the best fit to all the systems at all measured temperatures. Therefore, SAFT has predictive value for determining liquid-phase compositions in VLE of alkane + alkane systems.

The Aspen Plus ${ }^{\mathrm{TM}}$ simulation package was used to perform process simulation studies for the proposed Fischer-Tropsch process. For all the process simulation studies, the Redlich-Kwong-Soave (RKS) cubic equation of state was used. Like P-R, RKS does not accurately reproduce the solvent + wax phase behavior, but it can be used to give qualitative results for examining the design of the proposed F-T process.

It is interesting to note that many of the Aspen calculations dealing with the solvent + F-T wax give results that can be compared to results for the experimental results for true binary mixtures (e.g., hexane + hexatriacontane). For example, simulation results showed that as the solvent/non-solvent ratio was increased, the mixture critical point was found to shift to lower temperatures and pressures. This is analogous to the binary mixture critical points. The smaller the wax composition at the mixture critical point, the closer the critical point is to the solvent critical point. From the binary experimental data, it is also possible to examine both pressure- and temperature-induced retrograde behavior. In all the measured binary VLE data at temperatures above the critical point of hexane, it can be observed that at the highest pressures the heavy component solubility increases in the vapor phase as pressure is increased. Temperature-retrograde behavior can be directly observed in the experimental data for the hexane + hexatriacontane system. At a temperature of $622 \mathrm{~K}$ and a pressure of 53.4 bar, the vapor phase has a composition on the order of 0.01 mole fraction $\mathrm{C}_{36}$. When the temperature of the mixture is dropped to $573 \mathrm{~K}$ at constant pressure, the solution approaches the mixture critical point for that temperature and the vapor-phase composition increases to $\sim 0.03$.

One study using Aspen focused on using a solvent/non-solvent ratio of 20. For 
these simulations, a high makeup flowrate was generally needed, and the $\mathrm{E}_{\mathrm{s}} / \mathrm{ASF}_{\mathrm{s}}$ ratio tended to be large. Improved results, in terms of lower solvent makeup flow rates, V/P ratios, and $\mathrm{E}_{\mathrm{S}} / \mathrm{ASF}_{\mathrm{S}}$ ratios, were achieved in another study that used lower solvent/nonsolvent ratios. However, the higher extraction temperatures $(630-680 \mathrm{~K})$ that were associated with low solvent/non-solvent ratios raise concerns about catalyst deactivation.

For both high and low solvent/non-solvent ratios, operating conditions were obtained for which no AMW buildup occurred in the reactor slurry. Thus, Aspen simulations have essentially resolved a key issue in the viability of our proposed extraction process. For all simulations, the $\mathrm{E}_{\mathrm{s}} / \mathrm{ASF}_{\mathrm{s}}$ ratio was greater than one; thus, solvent recovery techniques more efficient than simple flash drums (e.g., distillation columns) will be required to make our process self-sufficient in terms of solvent. 


\section{References}

API-42. Properties of Hydrocarbons of High Molecular Weight Synthesized by Research Project 42 of the American Petroleum Institute. The Pennsylvania State University, University Park, PA, 1966.

Ambrose, D.; Tsonopoulos, C. Vapor-Liquid Properties of Elements and Compounds. 2. Normal Alkanes. J. Chem. Eng. Data 1995, 40, 531-546.

Chapman, W. G.; Gubbins, K. E.; Jackson, G.; and Radosz, M. New Reference Equation of State for Associating Liquids. Ind. Eng. Chem. Res. 1990, 29, 1709-1721.

Chapman, W. G., Jog, P. K., Joyce, P. C., and Thies, M. C. Vapor-Liquid Equilbria for

Long-Chain Alkanes in Supercritical Hexane. Presented at the AIChE 1998 Annual

Meeting, Miami Beach, FL, Nov 1998, paper 88f.

Doolittle, A. K. Specific Volumes of n-Alkanes. J. Chem. Eng. Data 1964, 9, 275-279.

Gude, M. T.; Rosenthal, D. J.; Teja, A. S. The Critical Properties of 1-Alkenes from 1Pentene to 1-Dodecene. Fluid Phase Equil. 1991, 70, 55-64.

Huang, S. H.; Radosz, M. Equation of State for Small, Polydisperse, and Associating Molecules. Ind. Eng. Chem. Res. 1990, 29, 2284-2294.

Huang, S. H.; Radosz, M. Equation of State for Small, Polydisperse, and Associating Molecules: Extension to Fluid Mixtures. Ind. Eng. Chem. Res. 1991, 30, 1994-2005.

Hutchenson, K. W. Fractionation of Petroleum Pitch by Supercritical Fluid Extraction: Experimental Phase Behavior and Thermodynamic Modeling. Ph.D. Dissertation, Clemson University, Clemson, SC, 1990.

Joyce, P. C.; Thies, M. C. Separation of Fischer-Tropsch Wax from Catalyst Using Supercritical Fluid Extraction. Quarterly Report Submitted to Department of Energy, Jan 1, 1996 - Mar 31, 1996.

Joyce, P. C.; Thies, M. C. Vapor-Liquid Equilibrium for Mixtures of Hexane and Squalane at Temperatures from 469.8 K to 623.3 K. J. Chem. Eng. Data 1997, 42, 321-323.

Joyce, P. C.; Thies, M. C. Vapor-Liquid Equilibrium for the Hexane + Hexadecane and Hexane +1 -Hexadecanol Systems at Elevated Temperatures and Pressures. J. Chem. Eng. Data 1998, 43, 819-822.

Joyce, P. C.; Leggett, B. E.; Thies, M. C. Vapor-Liquid Equilibrium for Model FischerTropsch Waxes (Hexadecane, 1-Hexadecene, and 1-Hexadecanol) in Supercritical Hexane. Fluid Phase Equil. 1999a, in press.

Joyce, P. C.; Gordon, J.; Thies, M. C. Vapor-Liquid Equilibria for the Hexane + Tetracosane and Hexane + Hexatriacontane Systems at Elevated Temperatures and Pressures. Fluid Phase Equil. 1999b, submitted for publication.

Morgan, D. L.; Kobayashi, R. Direct Vapor Pressure Measurements of Ten n-Alkanes in the C10-C28 Range. Fluid Phase Equil. 1994, 97, 211-242.

Nederbragt, G. W.; De Jong, J. J. Gas-Liquid Equilibria of Mixtures of N-Alkanes. Appl. Sci. Res. 1951, A3, 125-143.

Nikitin, E. D.; Pavlov, P. A.; Popov, A. P. Vapor-Liquid Critical Temperatures and Pressures of Normal Alkanes with from 19 to 36 Carbon Atoms, Naphthalene, and mTerphenyl Determined by the Pulse-Heating Technique. Fluid Phase Equil. 1997, 141, 155-164.

Pak, S. C.; Kay, W. B. The Critical Properties of Binary Hydrocarbon Systems. Ind. 
Eng. Chem. Fund. 1972, 11, 255-267.

Peters, C. J.; De Roo, J. L.; Lichtenthaler, R. N. Measurements and Calculations of Phase Equilibria of Binary Mixtures of Ethane + Eicosane. Part I: Vapor + Liquid Equilibria. Fluid Phase Equil. 1987, 34, 287-308.

Peters, C. J.; Van Der Kooi, H. J.; De Roo, J. L.; de Swaan Arons, J.; Gallagher, J. S.; Levelt Sengers, J. M. H. The Search for Tricriticalities in Binary Mixtures of NearCritical Propane and Normal Paraffins. Fluid Phase Equil. 1989, 51, 339-351.

Peters, C. J.; De Roo, J. L.; de Swaan Arons, J. Measurements and Calculations of Phase Equilibria in Binary Mixtures of Propane + Tetratriacontane. Fluid Phase Equil. 1992, 72, 251-266.

Radosz, M.; Adidharma, H. Square-Well SAFT Equations of State for Homopolymeric and Heteropolymeric Fluids. Presented at the $8^{\text {th }}$ International Conference on Properties and Phase Equilibria for Product and Process Design, Noordwijkerhout, The Netherlands, April 1998.

Stephenson, R. M.; Malanowski, S. Handbook of the Thermodynamics of Organic Compounds. Elsevier: New York, 1987.

Stevenson, R. L. Fluid-Phase Equilibria and Critical Phenomena for the Squalane-Water System. M. S. Thesis, Clemson University, Clemson, SC, 1992.

Teja, A. S.; Lee, R. J.; Rosenthal, D.; Anselme, M. Correlation of the Critical Properties of Alkanes and Alkanols. Fluid Phase Equil. 1990, 56, 153-169.

Van Konynenburg, P.H.; Scott, R.L. Critical Lines and Phase Equilibria in Binary Van Der Waals Mixtures. Phil. Trans. Roy. Soc. 1980, 298, 495-540.

Zhuravlev, N. D.; Siepmann, J. I. Exploration of the Vapor-Liquid Phase Equilibria and Critical Points of Triacontane Isomers. Fluid Phase Equil. 1997, 134, 55-61. 


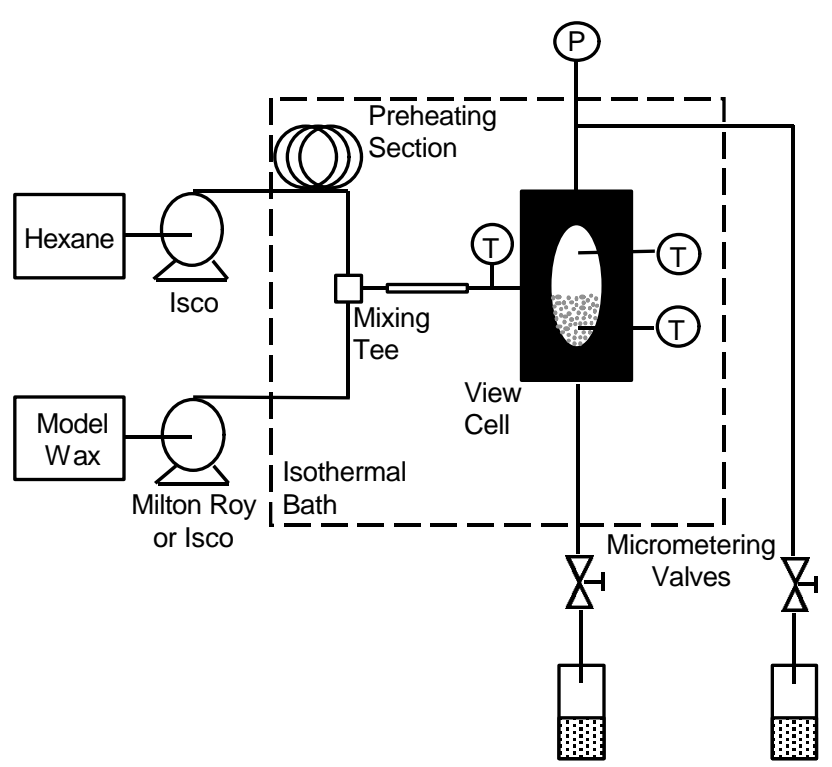

Figure 1. Schematic of the continuous-flow apparatus.

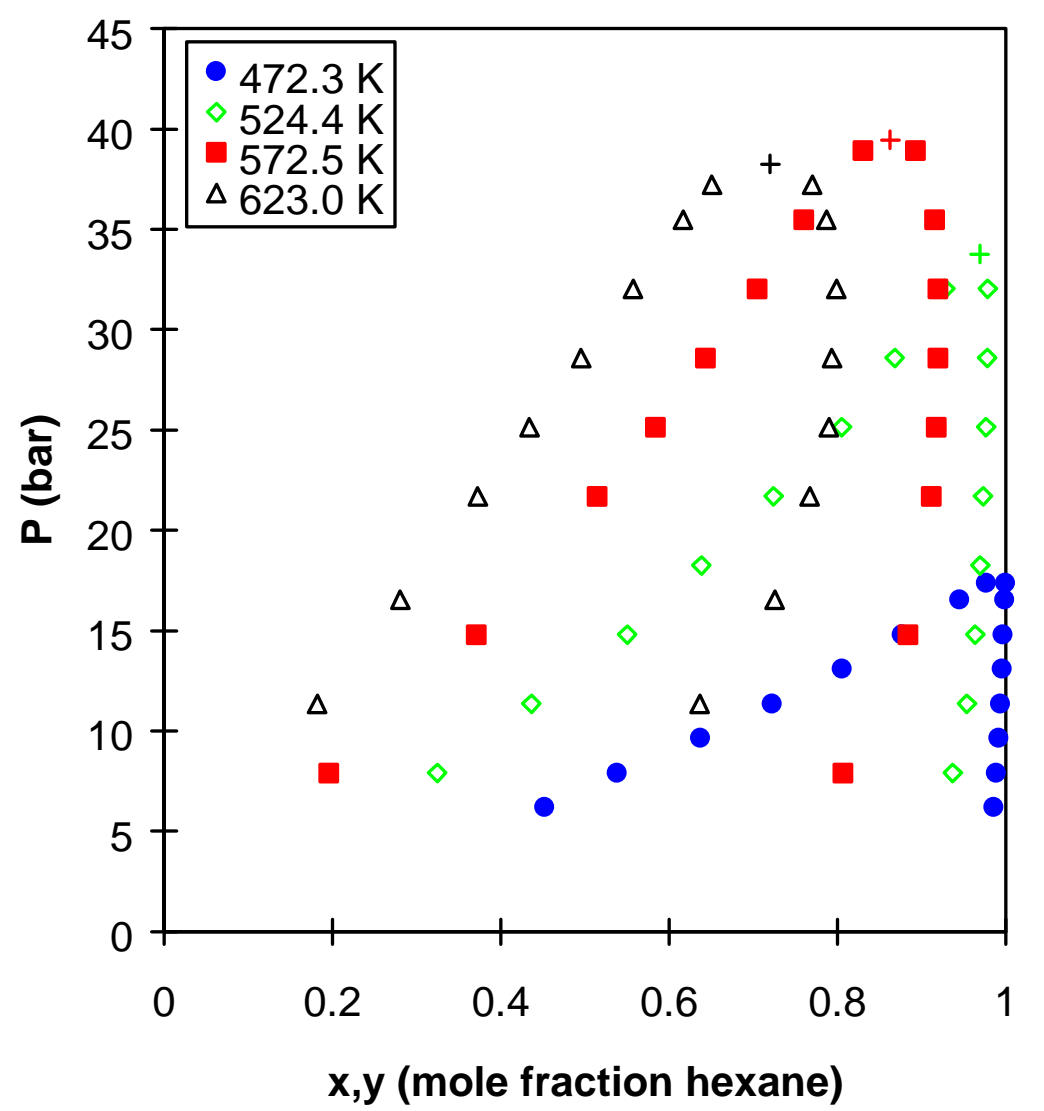

Figure 2. Pressure vs composition diagram for the hexane + hexadecane system. For all $\mathrm{P}-\mathrm{x}-\mathrm{y}$ diagrams shown, the + 's denote mixture critical points. 


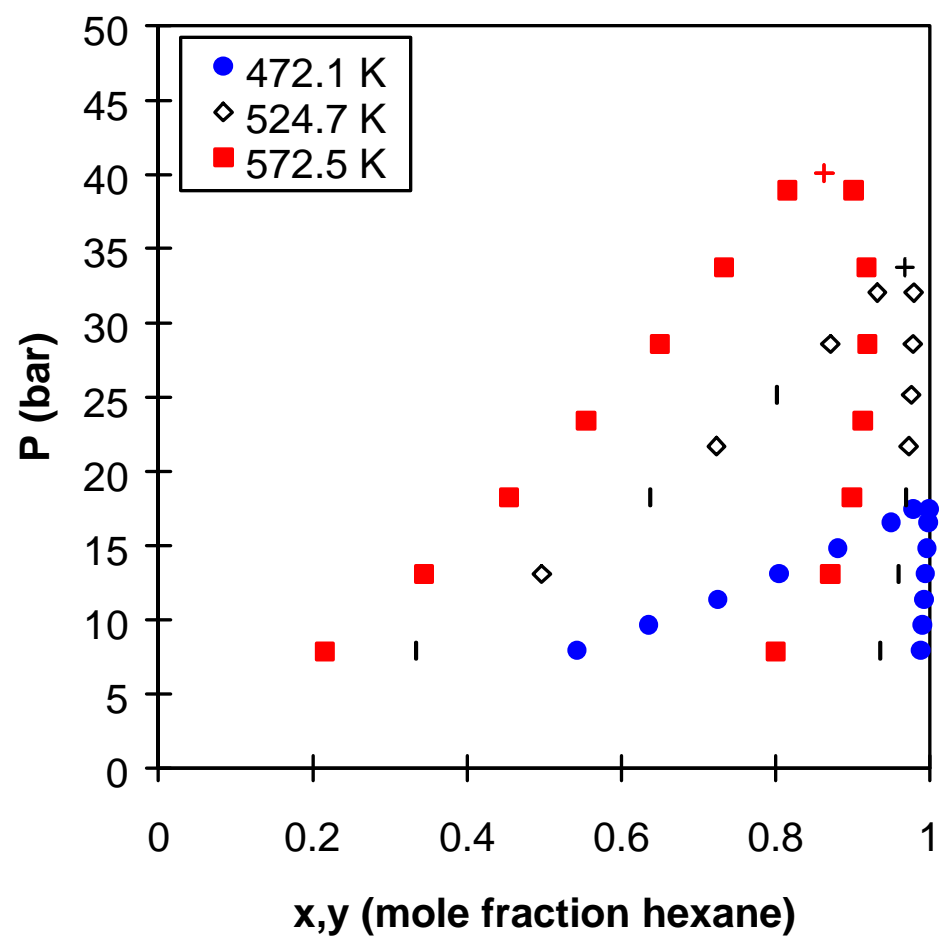

Figure 3. Pressure vs composition diagram for the hexane +1 -hexadecene system.

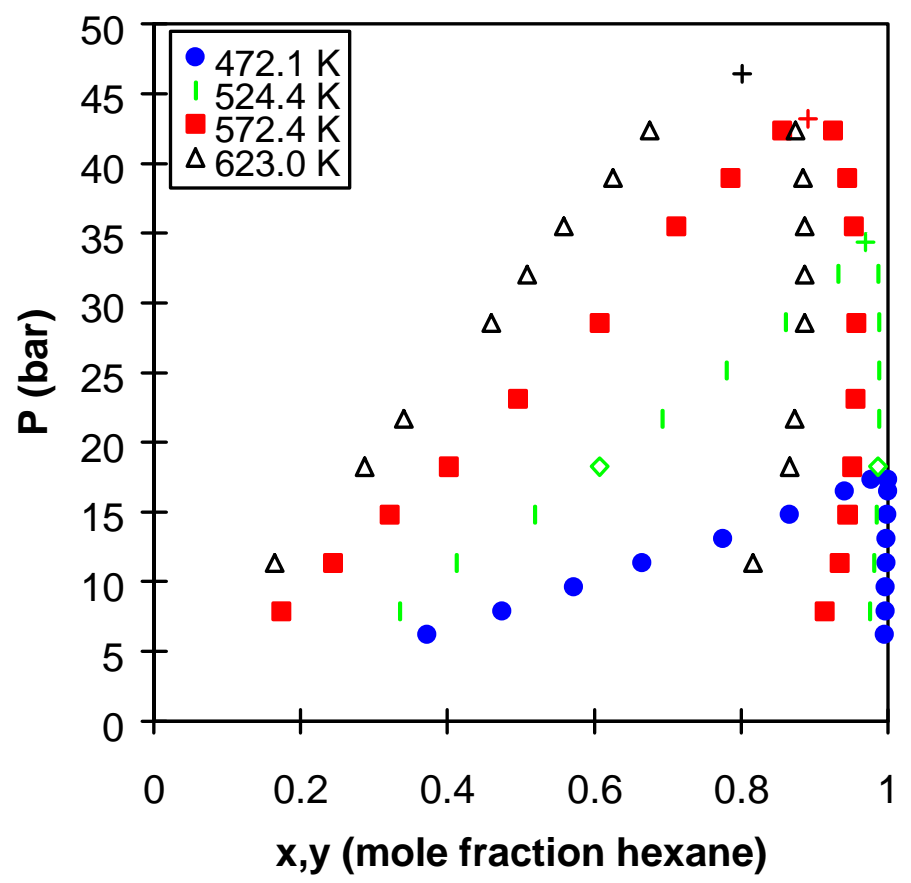

Figure 4. Pressure vs composition diagram for the hexane +1 -hexadecanol system. 


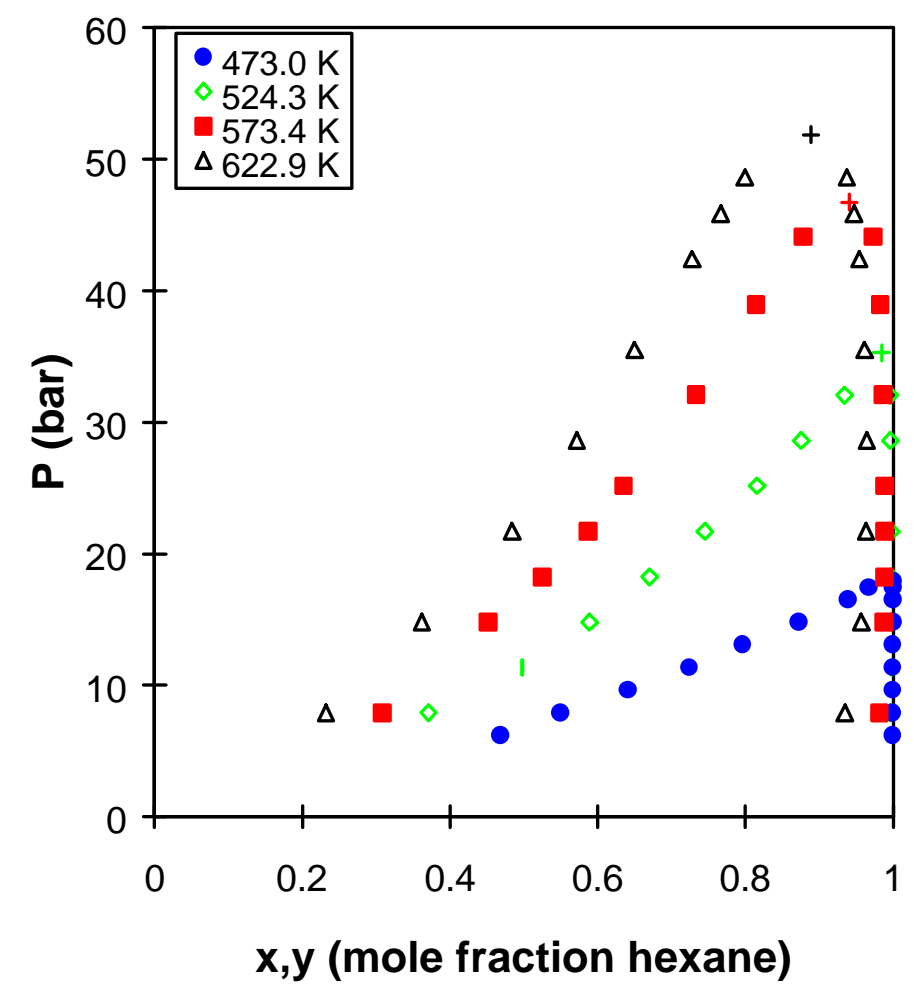

Figure 5. Pressure vs composition diagram for the hexane + tetracosane system.

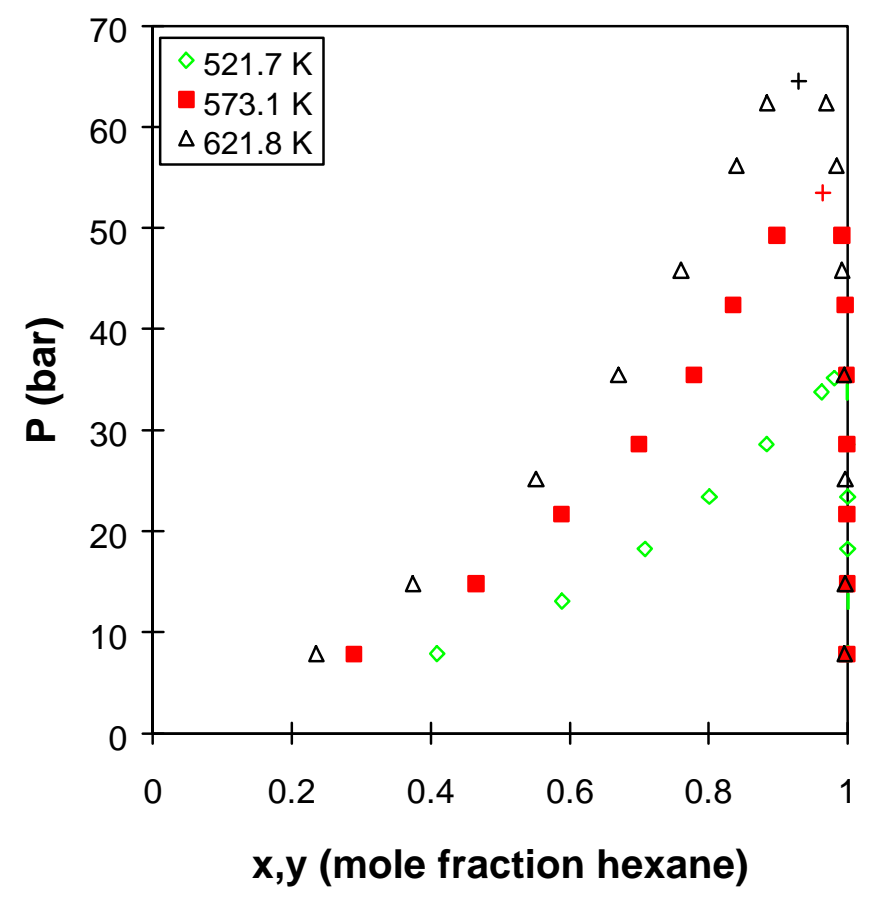

Figure 6. Pressure vs composition diagram for the hexane + hexatriacontane system. 


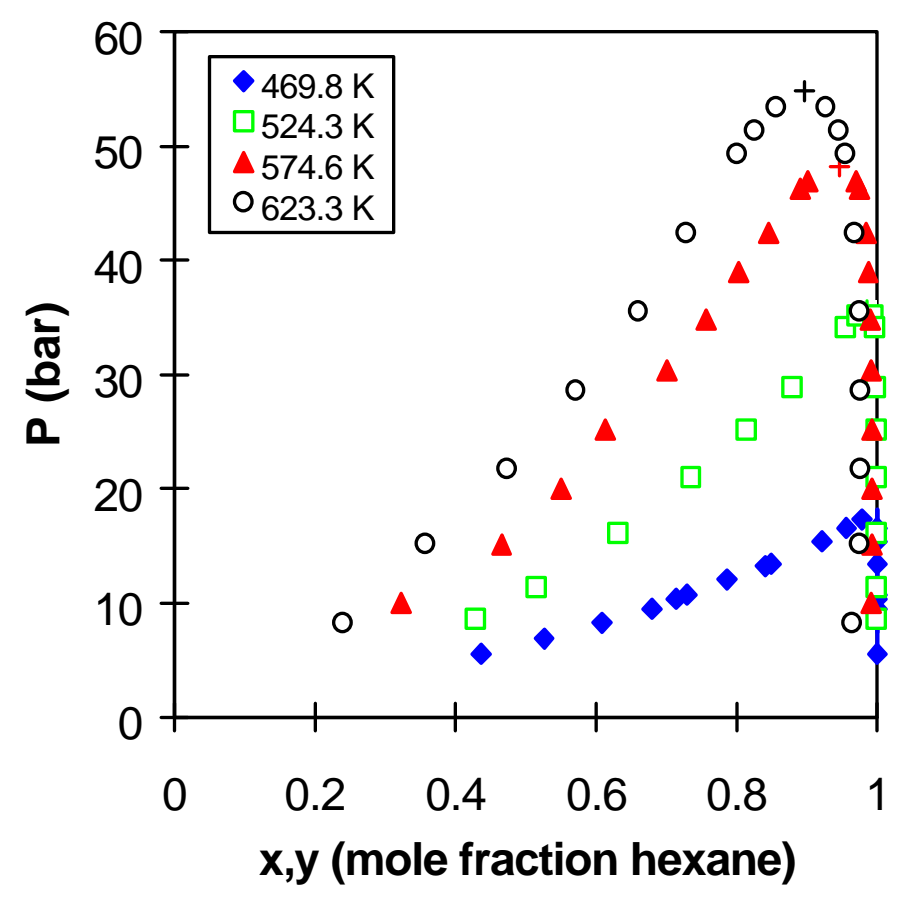

Figure 7. Pressure vs composition diagram for the hexane + squalane system.

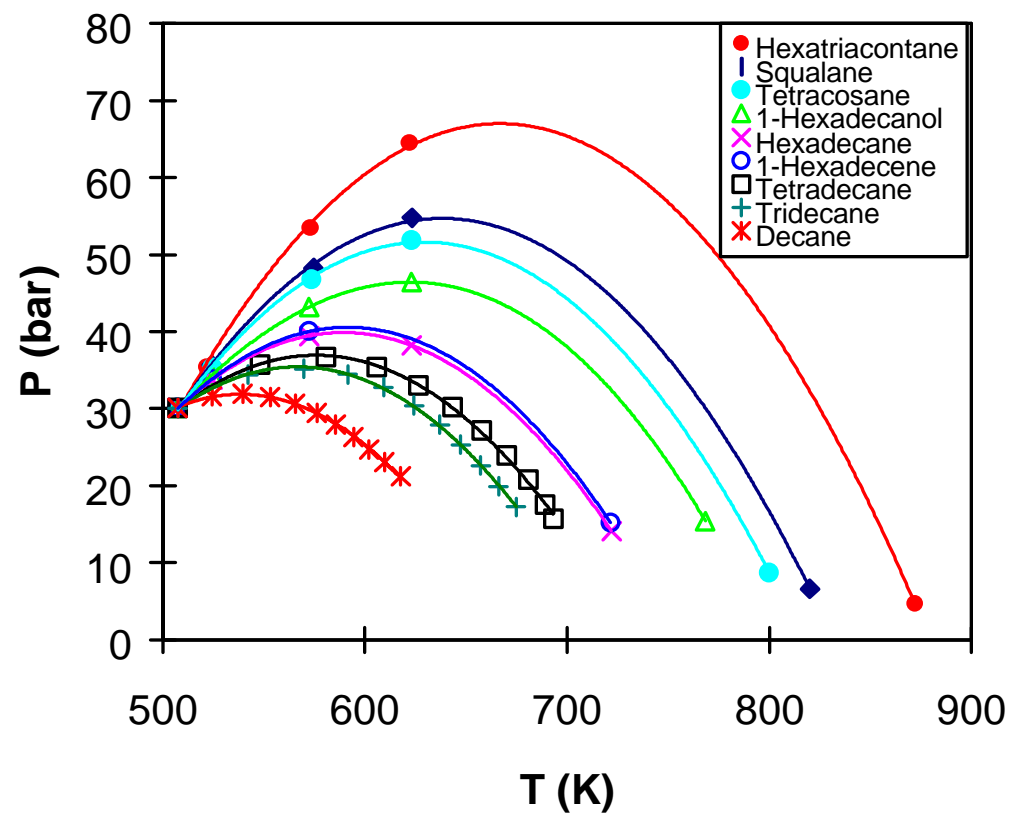

Figure 8. Critical locus curves for mixtures of hexane with model F-T waxes. 

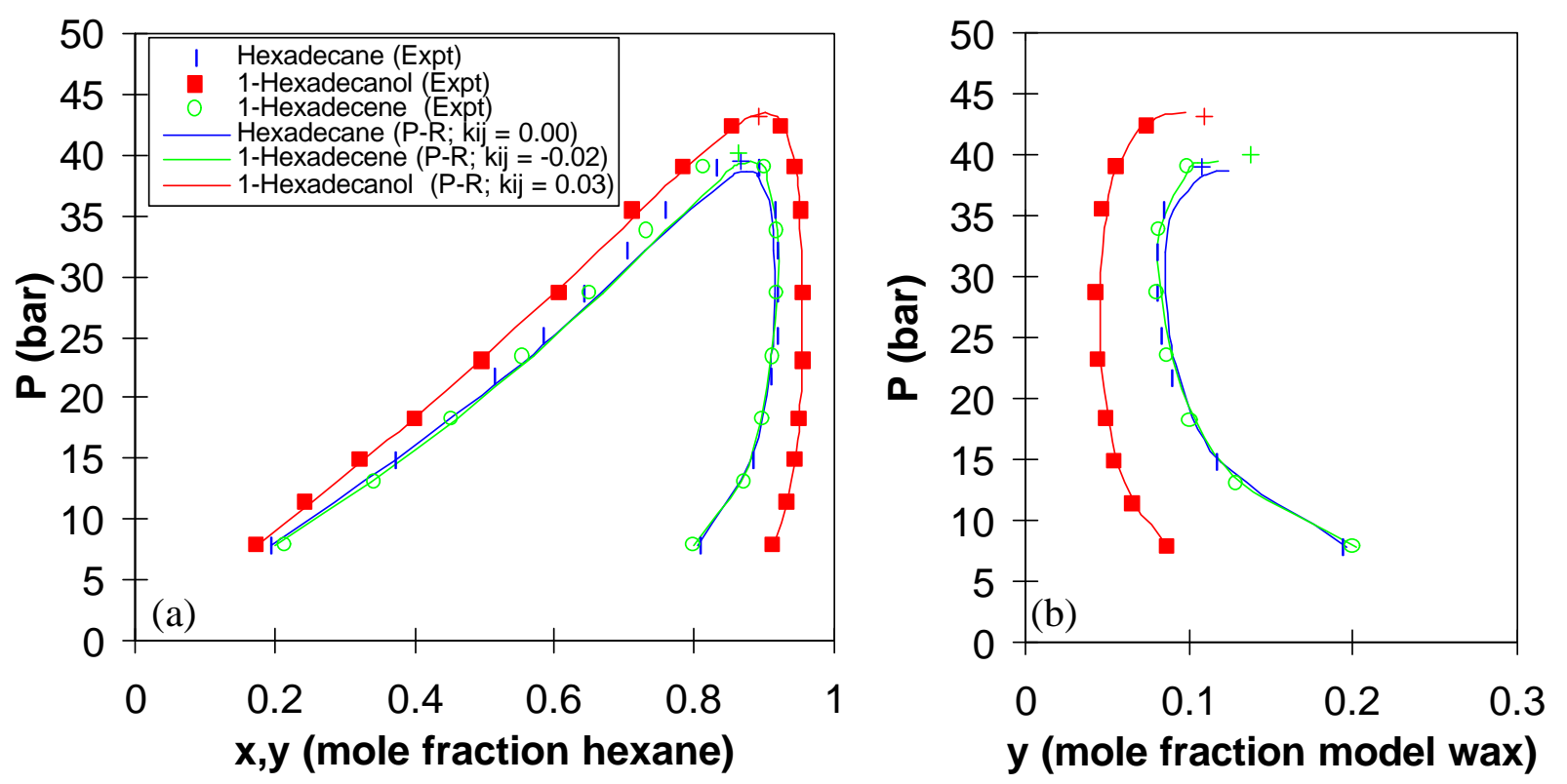

Figure 9. Comparison of the experimental and P-R calculated compositions for binary mixtures of hexane with $\mathrm{C}_{16}$ backbone model waxes at $573 \mathrm{~K}$.
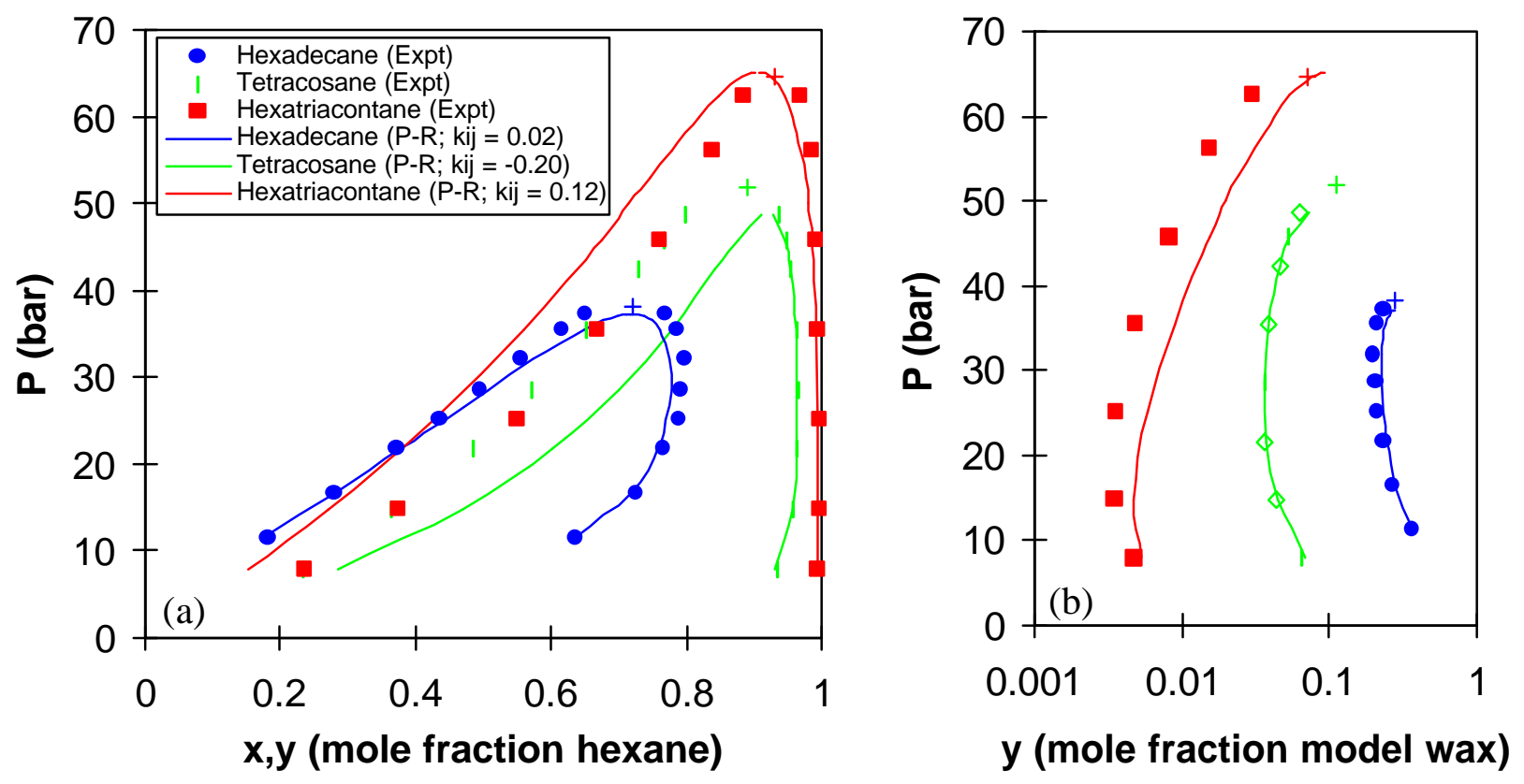

Figure 10. Comparison of the experimental and P-R calculated compositions for the binary mixtures of hexane with n-alkane model waxes at $623 \mathrm{~K}$. 


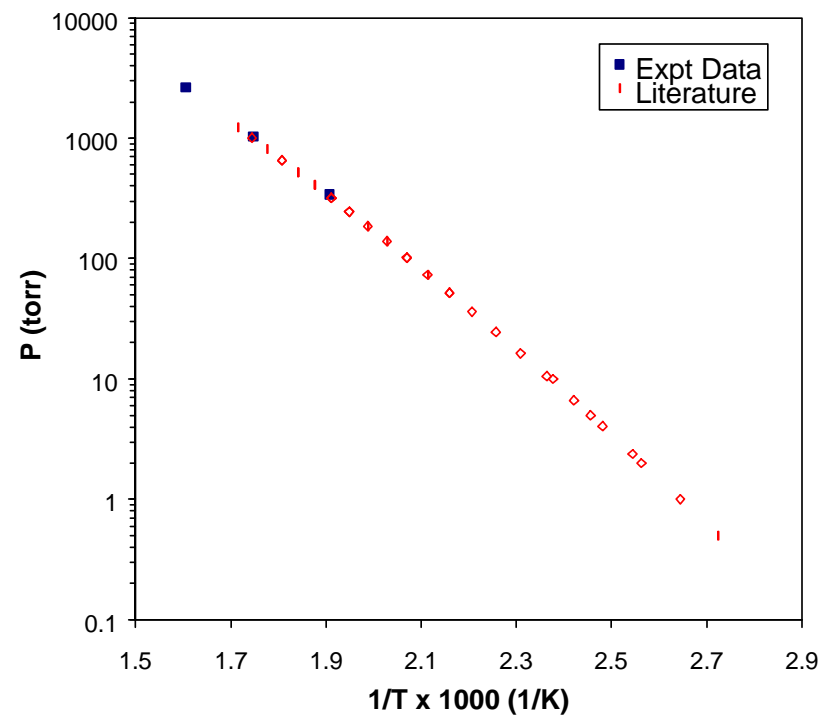

Figure 11. Comparison of the vapor pressure extrapolated from binary VLE data with measured $\mathrm{P}^{\text {sat }}$ data for hexadecane.

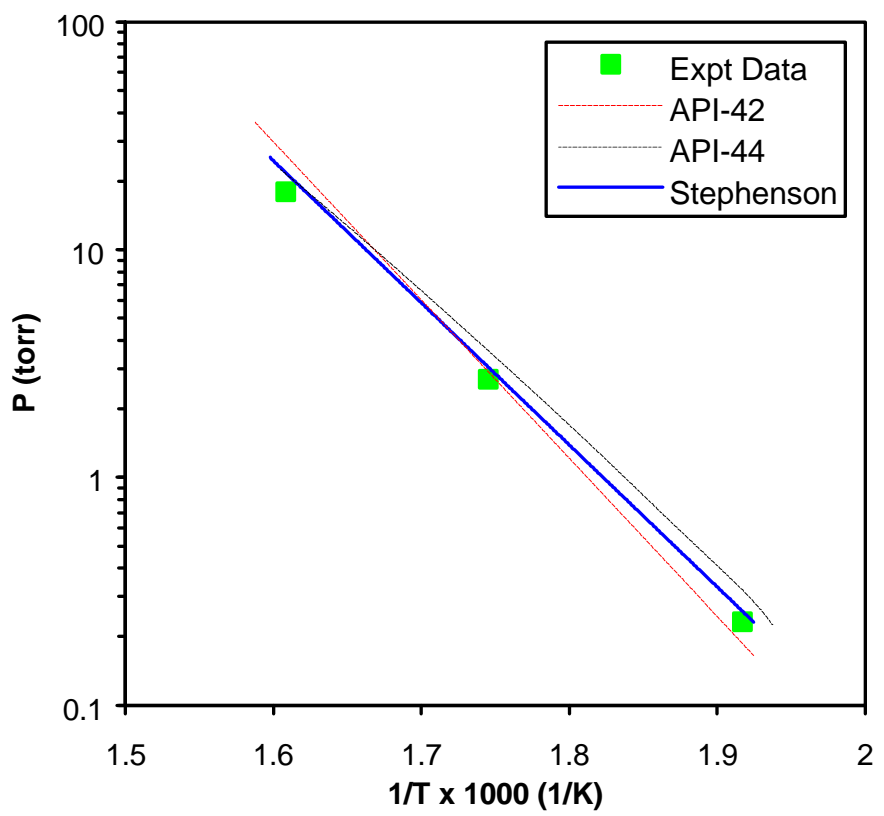

Figure 12. Comparison of literature data sources versus the vapor pressure extrapolated from VLE data for $\mathrm{C}_{6}+\mathrm{C}_{36}$. 


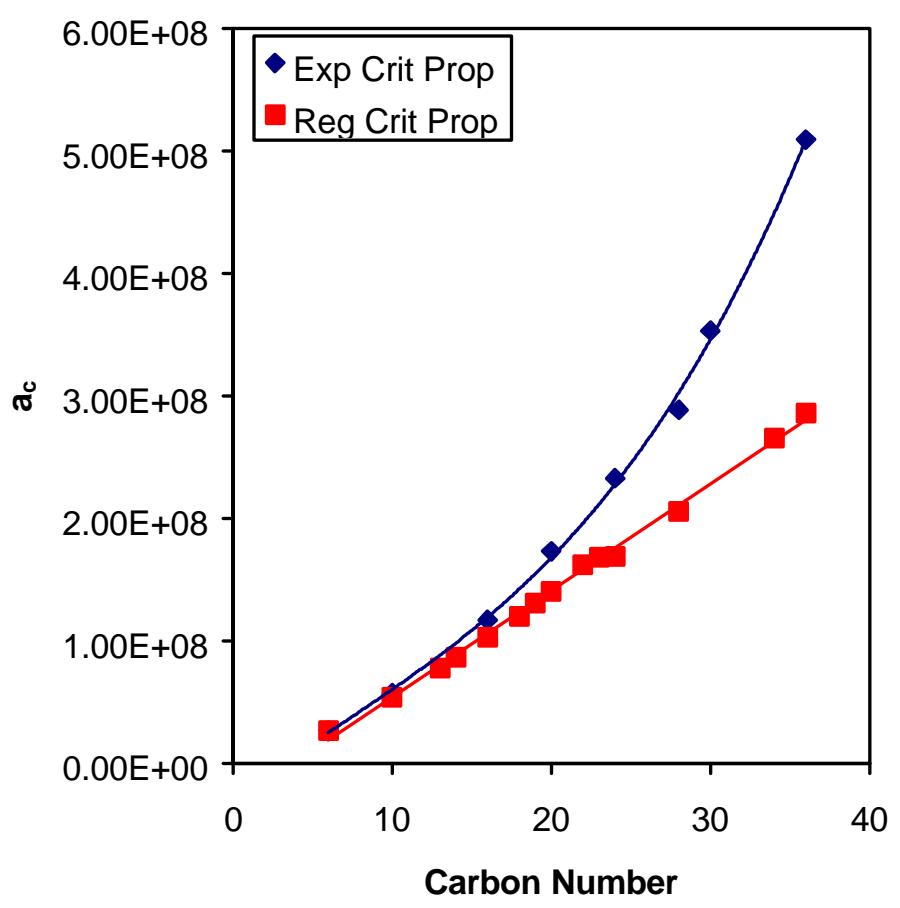

Figure 13. The variation of the $\mathrm{a}_{\mathrm{c}}$ parameter of $\mathrm{P}-\mathrm{R}$ with alkane chain length using the experimental vs. regressed critical properties.

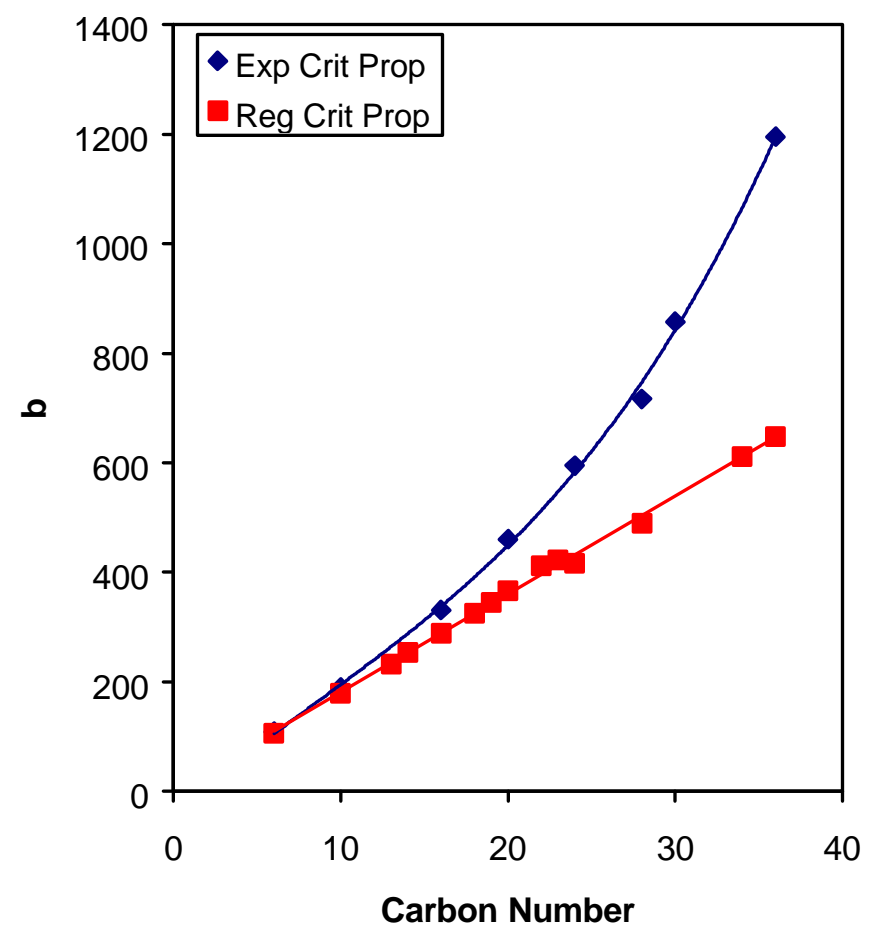

Figure 14. The variation of the $\mathrm{b}$ parameter of P-R with alkane chain length using the experimental vs. regressed critical properties. 

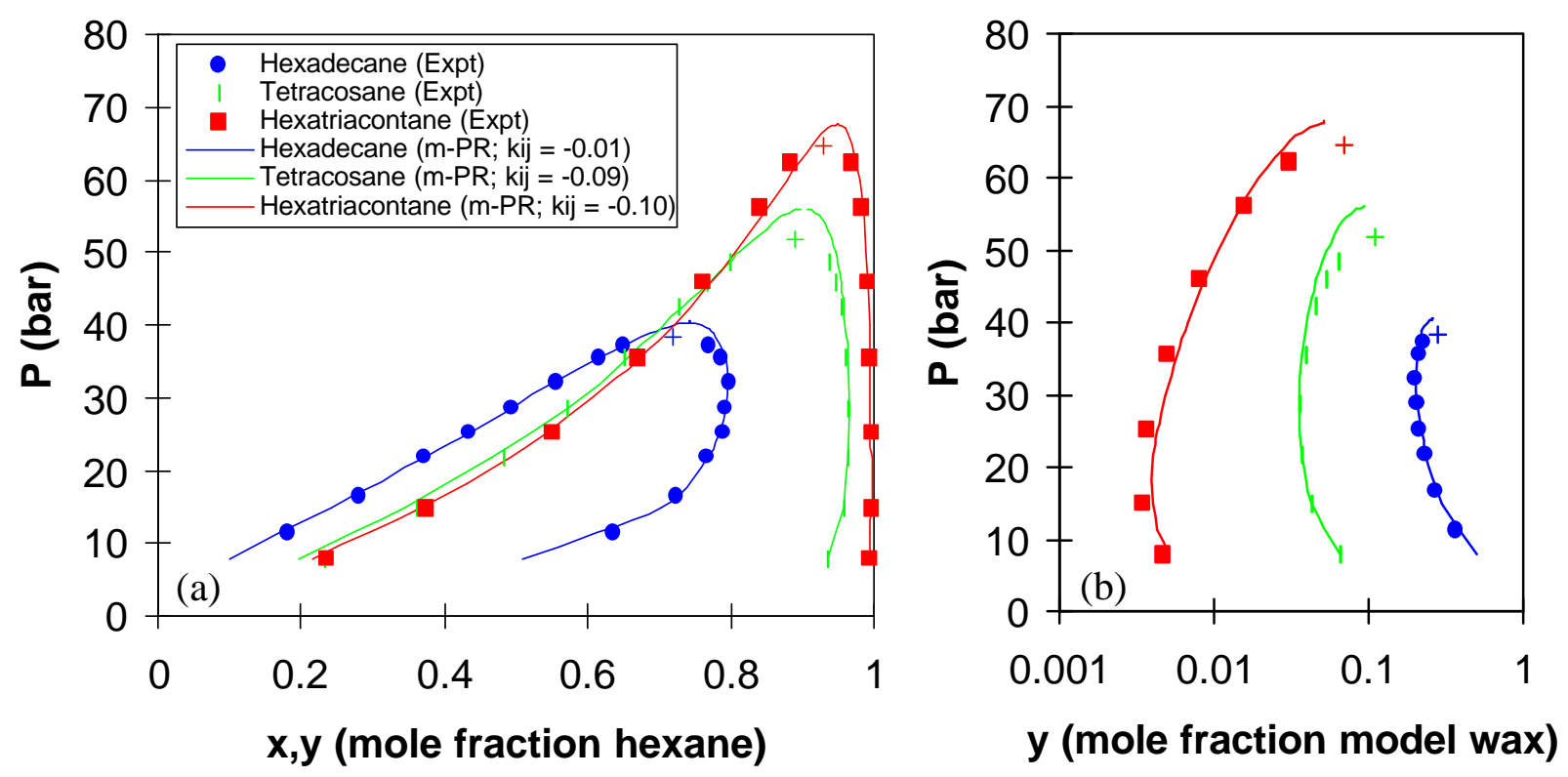

Figure 15. Comparison of the experimental and m-PR calculated compositions for the binary mixtures of hexane with n-alkane model waxes at $623 \mathrm{~K}$.

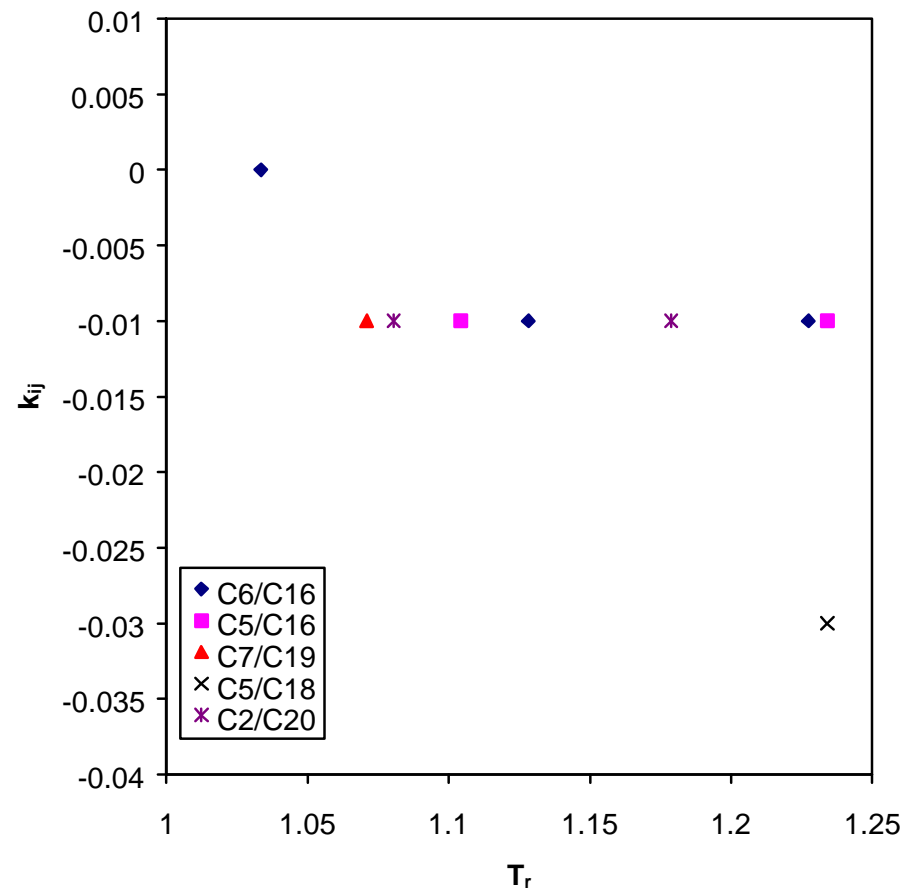

Figure 16. Variation of optimized $\mathrm{k}_{\mathrm{ij}}$ 's versus solvent reduced temperature when the solute is smaller than $\mathrm{C}_{20}$. (Data for the the $\mathrm{C}_{5}+\mathrm{C}_{16}, \mathrm{C}_{5}+\mathrm{C}_{18}$, and $\mathrm{C}_{7}+\mathrm{C}_{19}$ systems from Nederbragt and De Jong (1951); data for $C_{2}+C_{20}$ from Peters et al. (1987)) 


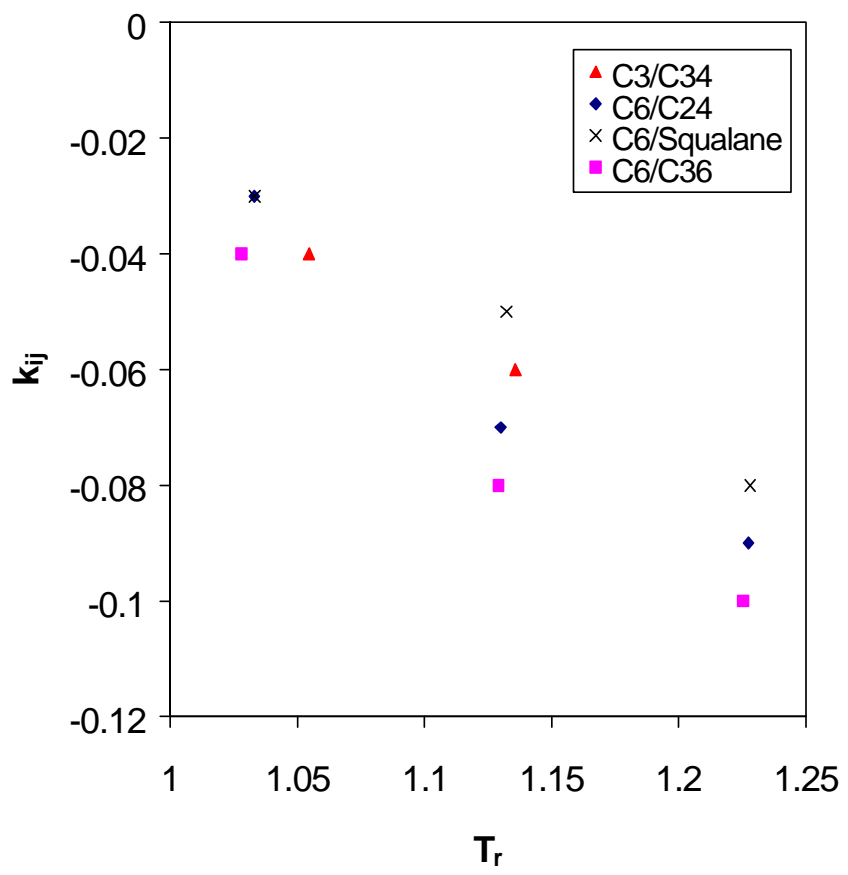

Figure 17. Variation of optimized $\mathrm{k}_{\mathrm{ij}}$ 's versus solvent reduced temperature when the solute is larger than $C_{24}$. (Data for the the $C_{3}+C_{34}$ system from Peters et al. (1992))
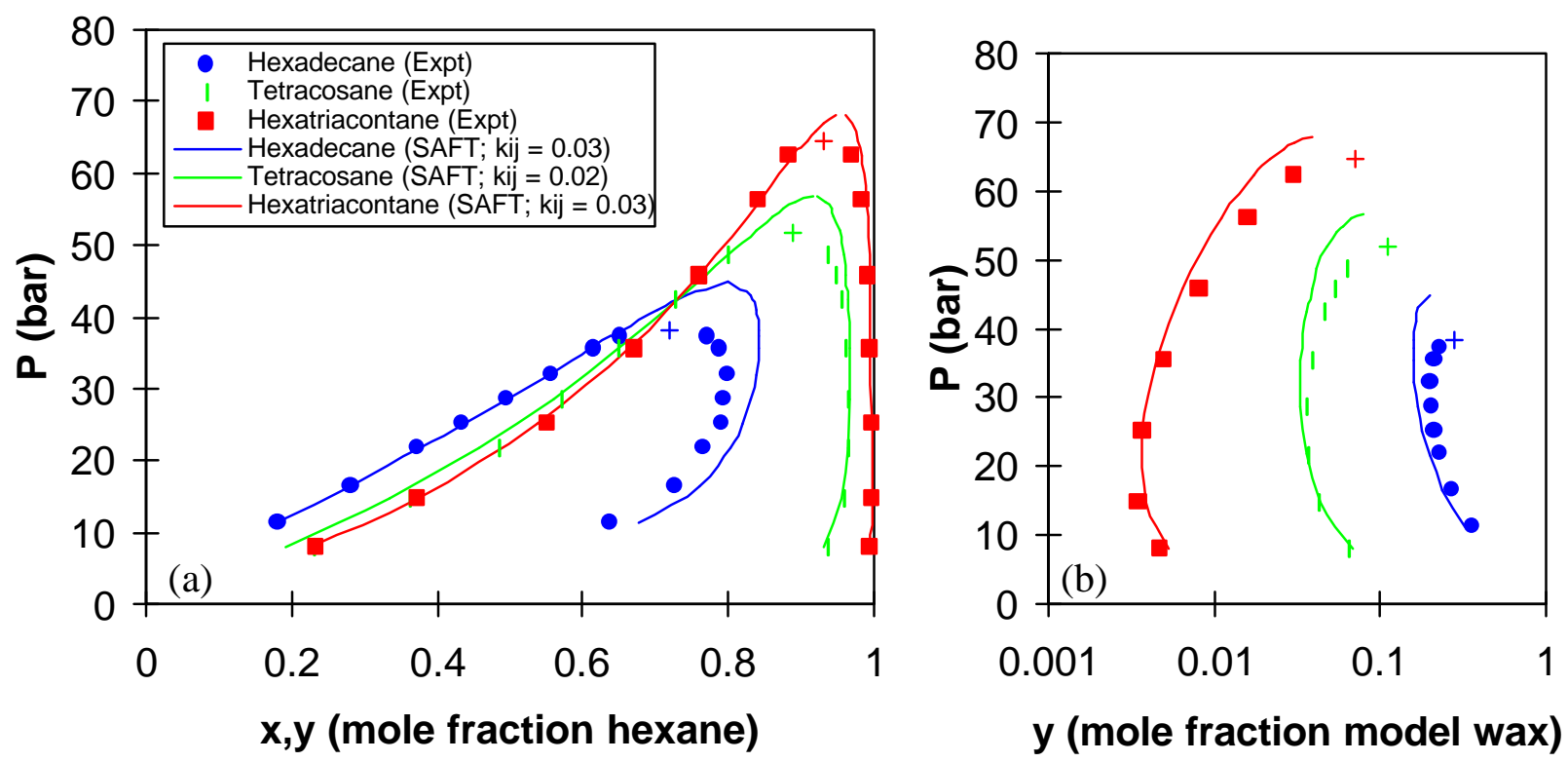

Figure 18. Comparison of the experimental and SAFT calculated compositions for the binary mixtures of hexane with $\mathrm{n}$-alkane model waxes at $623 \mathrm{~K}$. 


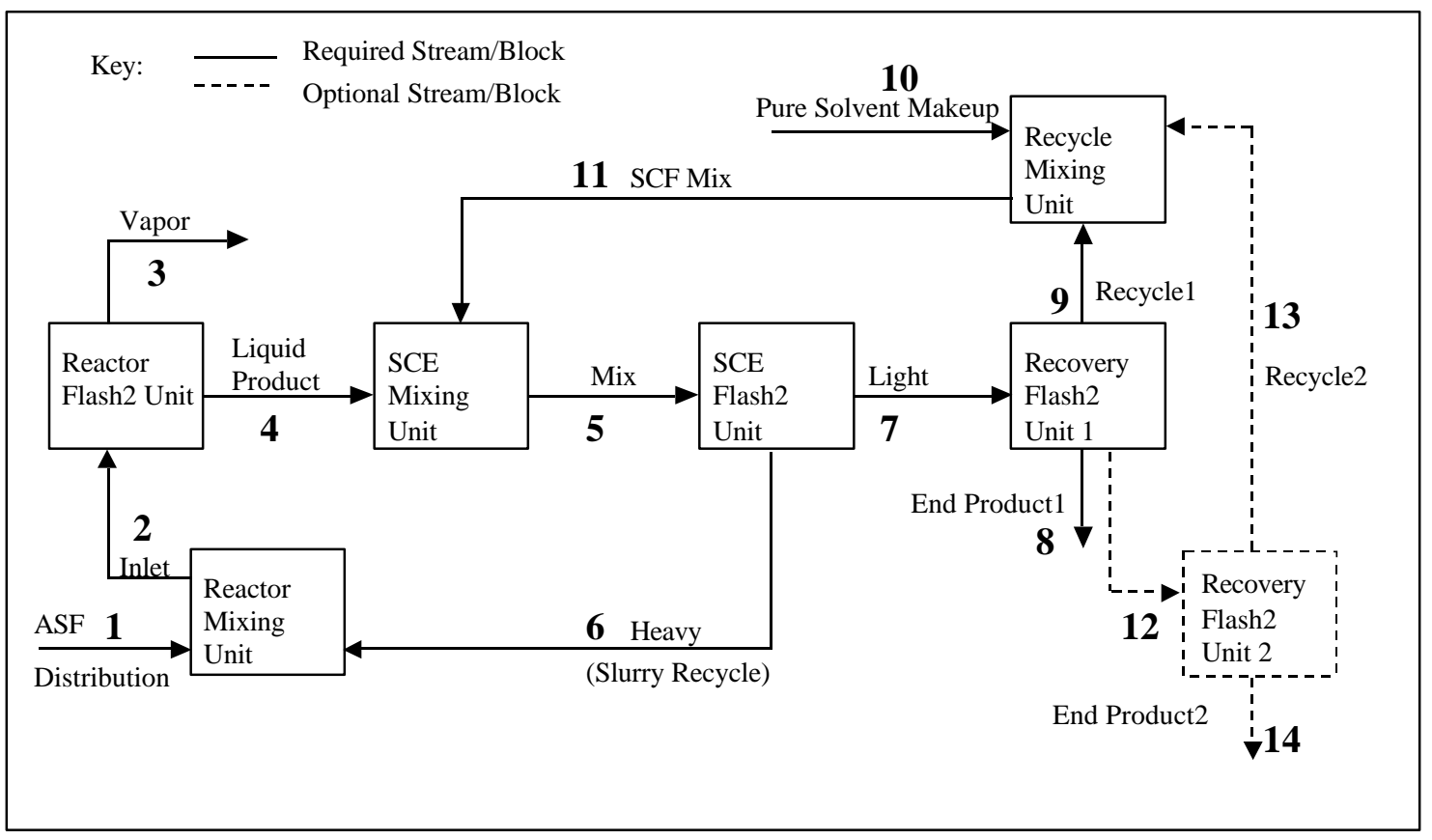

Figure 19. Schematic diagram of near-critical extraction process for separating FischerTropsch wax from catalyst.

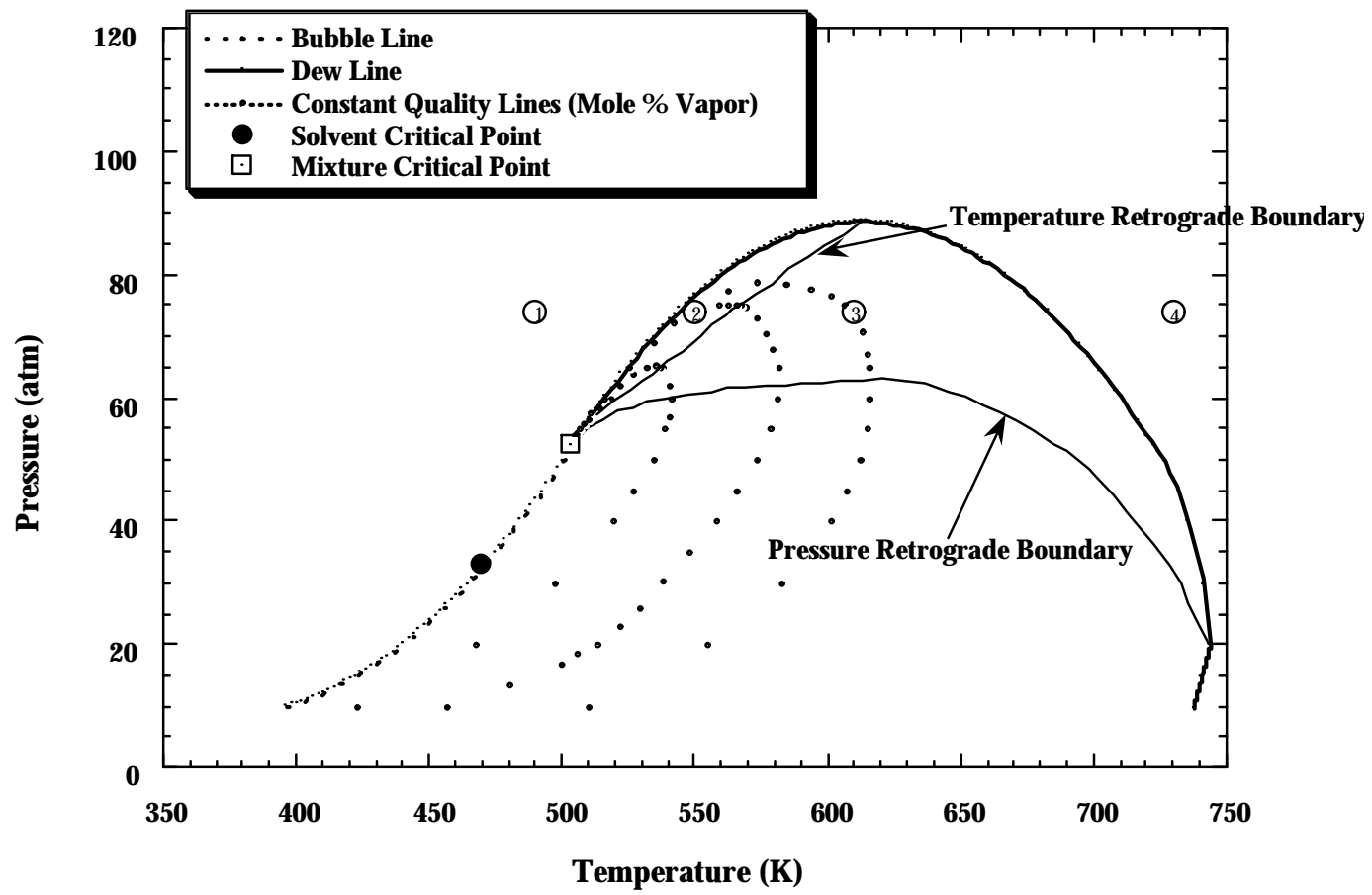

Figure 20. Constant composition PT diagram showing the retrograde region for a mixture containing $n$-pentane solvent and F-T product in a 20:1 molar ratio. 